\title{
The role of endoglin in post-ischemic revascularization
}

Elena Núñez-Gómez ${ }^{1,2}$, Miguel Pericacho ${ }^{1,2}$, Claudia Ollauri-Ibáñez ${ }^{1,2}$, Carmelo Bernabéu3, José M. López-Novoa ${ }^{1,2}$

${ }^{1}$ Renal and Cardiovascular Research Unit, Department of Physiology and Pharmacology, University of Salamanca, Salamanca, Spain.

${ }^{2}$ Biomedical Research Institute of Salamanca (IBSAL), Salamanca, Spain.

${ }^{3}$ Centro de Investigaciones Biológicas, Spanish National Research Council (CIB, CSIC), and Centro de Investigación Biomédica en Red de Enfermedades Raras (CIBERER), Madrid, Spain.

Full address for correspondence:

José M. López-Novoa

Telephone: +34677554336

Fax: +34 923294669

e-mail address: jmlnovoa@usal.es 


\section{Abstract}

Following arterial occlusion, blood vessels respond by forming a new network of functional capillaries (angiogenesis), by re-organizing pre-existing capillaries through the recruitment of smooth muscle cells to generate new arteries (arteriogenesis) and by growing and remodeling pre-existing collateral arterioles into physiologically relevant arteries (collateral development). All these processes result in the recovery of organ perfusion. The importance of endoglin in post-occlusion reperfusion is sustained by several observations: i) endoglin expression is increased in vessels showing active angiogenesis/remodeling; ii) genetic endoglin haploinsufficiency in humans causes deficient angiogenesis; and iii) the reduction of endoglin expression by gene disruption or the administration of endoglin-neutralizing antibodies reduces angiogenesis and revascularization. However, the precise role of endoglin in the several processes associated with revascularization has not been completely elucidated and, in some cases, the function ascribed to endoglin by different authors is controversial. The purpose of this review is to organize in a critical way the information available for the role of endoglin in several phenomena (angiogenesis, arteriogenesis, and collateral development) associated with post-ischemic revascularization.

\section{Keywords}

Angiogenesis; Arterial occlusion; Arteriogenesis; Collateral growth; Endoglin; Ischemia; Revascularization; Vascular remodeling. 


\section{INTRODUCTION}

Adult mammals have developed a set of physiological mechanisms that regulate the supply of nutrients and oxygen to tissues according to their requirements. When an organ changes its metabolism in an acute way, blood flow along arteries, arterioles and capillaries can be controlled, depending on the metabolic requirements of this organ, to maintain a balance between the oxygen and nutrient requirements, the removal of waste products, and the blood flow supply. Acute blood flow regulation is managed by adjusting the contraction or relaxation of smooth muscle fibers in the walls of arterioles. However, when an organ or tissue suffers a long-term lack of adequate blood supply (ischemia), some other mechanisms are activated to correct this deficiency. Ischemia comprises not only an insufficiency of oxygen but also a reduced availability of nutrients and an inadequate removal of metabolites. The response to ischemic situations includes a coordinated set of processes: i) "de novo" formation of a network of functional capillaries by budding off of endothelial cells (ECs) from the walls of preexisting capillaries (angiogenesis), ii) transformation of pre-existing capillaries in conductance arteries and veins (arteriogenesis) and iii) growth and remodeling of pre-existing low flow collateral arterioles that connect main arteries to physiologically relevant arteries (collateral development) [1]. This last process is also called arteriogenesis by several authors [2]. The contribution of each of these processes to revascularization after arterial obstruction depends on the organ perfused and the velocity of the arterial occlusion (acute or progressive).

During angiogenesis, preexisting ECs perform highly orchestrated morphogenic events that include basement membrane degradation, EC sprouting and branching, vessel lumen formation, vessel anastomosis and maturation, and mural cell recruitment, resulting in a new vascular network that provides blood to the hypoxic tissue $[3,4]$.

A different strategy to generate adequate blood flow for the metabolic demand of the tissue after ischemia is vascular remodeling, including arteriogenesis and collateral growth or development. Despite the considerable terminological confusion that has even stimulated the writing of specific reviews regarding the nomenclature used [5], there is an unambiguous difference between arteriogenesis and collateral growth: arteriogenesis is the appearance of new arteriolar structures from preexisting capillaries, whereas collateral growth is the development and remodeling (anatomic increase in lumen area and wall thickness) of preexisting arterio-arterial anastomoses to form functional conducting arteries that significantly contribute to tissue perfusion [1]. During the arteriogenesis process, the 
persistent increased oxygen demand by the ischemic organ induces arteriolar vasodilatation and increased blood flow in downstream vessels. Consequently, increased shear stress induces the maturation of capillaries towards arteries. In this manner, preexisting EC channels become covered by pericytes and vascular smooth muscle cells (VSMCs), which provide stability and control of the perfusion of newly formed arteries. During the collateral growth process, upon occlusion of an artery, the blood flow is redirected into preexisting arterio-arterial anastomoses (collateral vessels) due to the sudden pressure gradient between the high pressure in pre-occlusive regions and the low pressure in the post-occlusive areas that are connected by these collaterals. Thus, these arteries are exposed to increased mechanical forces such as pulsatile fluid shear stress [6]. As a consequence of the increased shear stress, the endothelium of the collateral arteriolar connections is activated, resulting in increased release of nitric oxide (NO), vascular endothelial growth factor (VEGF) and monocyte-attracting proteins such as monocyte chemoattractant protein-1 (MCP-1), as well as an upregulation of adhesion molecules (VCAM-1, ICAM-1, among others). Upon adherence and extravasation, monocytes promote vascular wall development by supplying growth factors and cytokines such as granulocyte-monocyte colony-stimulating factor (GM-CSF) or transforming growth factor- $\beta 1$ (TGF- $\beta 1$ ) [7-10]. All these mechanisms are described in detail later in this review.

It has been reported that angiogenic processes take place mainly in the microvascular circulation, whereas the macrovascular endothelium mainly drives arteriogenesis and vascular remodeling. While both have common signaling routes and responses, cell-by-cell analysis shows differential gene expression patterns, suggesting the presence of different highly regulated processes [11].

Inadequate angiogenesis or arteriogenesis is responsible for several types of diseases (4-6): (i) Pathologies with excessive angiogenesis/vascular remodeling including hemangiomas, psoriasis, Kaposi's sarcoma, ocular neovascularization and retinopathy of prematurity, rheumatoid arthritis, endometriosis, atherosclerosis and, the most studied, tumor growth and metastasis; (ii) Pathologies with poor angiogenesis/vascular remodeling, which include myocardial ischemia, peripheral limb ischemia, cerebral ischemia, delayed wound healing and impaired ulcer healing; and (iii) Pathologies with defective angiogenesis/vascular remodeling, in which the number of formed vessels is normal, but their structure and cellular composition is abnormal, such as arteriovenous malformations, telangiectasias or even tumor vessels, in which angiogenesis is not only excessive but also defective. 
As described above, ECs play a main role in both angiogenic and vascular remodeling processes, and many endothelium-related proteins and soluble factors are also involved in this process. In this context, endoglin (CD105), a co-receptor for several members of the TGF$\beta$ family expressed mainly in ECs, has been shown to be essential for the correct course of angiogenic processes [12-14]. Endoglin expression is enhanced in endothelium during active angiogenesis, both in non-tumor and tumor tissues [15, 16], and endoglin expression specifically rises at the angiogenic edge where vessel sprouting occurs [17]. A lack of endoglin or defective endoglin function results in impaired angiogenesis, revascularization and tumor growth [18-22]. Moreover, endoglin is used as a biomarker for a poor prognosis in several cancers [23, 24], and endoglin-neutralizing antibodies have demonstrated antitumor angiogenesis properties, as recently reviewed $[25,26]$. Additionally, a new role for endoglin in integrin-mediated angiogenic and vascular remodeling processes can be suggested in light of the recent discovery that endoglin is involved in the regulation of leukocyte recruitment [27] and in integrin-dependent cell adhesion processes, including pericyte attachment to ECs [28]. These data suggest that endoglin is a potential target for the regulation of defective or excessive angiogenesis. However, the mechanisms by which endoglin contributes to vascularization mechanisms have not been fully elucidated.

The purpose of the present review is to organize in a critical way the information available regarding the role of endoglin in the different phenomena associated with post-ischemic revascularization, and the cellular and molecular mechanisms involved in these phenomena.

\section{VASCULARIZATION EVENTS}

\section{Vessel organization}

Capillaries and small vessels are the major protagonists of angiogenesis. The vascular wall in these vessels is composed of the vascular endothelium and mural cells. The vascular endothelium is a cell monolayer that lines all blood-contacting surfaces in the circulatory system. Its strategic location allows the endothelium to detect changes in oxygen and nutrient availability, blood flow, shear stress or arterial pressure and to initiate vascular processes in response to these changes. Thus, following several stimuli, the endothelium produces a wide variety of mediators that communicate events inside the vessel lumen to mural cells [7].

The term mural cell refers generally to VSMCs and pericytes, both of which are involved in the formation of normal vasculature and are responsive to VEGF [29]. Pericytes are embedded in 
the basement membrane of the smallest blood vessels, where they communicate with ECs by means of both direct physical contact and paracrine signaling and are responsible for vessel stabilization and maturation [30].

\section{Hypoxia as the main angiogenic stimulus: HIF-1 $\alpha$ and VEGF as principal mediators}

Impairment of the blood supply to an organ leads to the generation of a hypoxic microenvironment because the oxygen supply is lower than the oxygen demand of this organ. In the hypoxic microenvironment, the cellular response to low oxygen bioavailability involves the accumulation of the hypoxia-inducible transcription factor 1 (HIF-1). Under normoxic conditions, the cytoplasmic HIF-1 alpha subunit (HIF-1 $\alpha$ ) is ubiquitinated by the von HippelLindau factor (pVHL) ubiquitin-ligase domain and subsequently degraded in the proteasome. HIF-1 $\alpha$ has an oxygen-dependent degradation domain (ODD), which is hydroxylated by enzymes that are directly dependent on $\mathrm{O}_{2}$ as a cofactor. The decreased $\mathrm{O}_{2}$ bioavailability during hypoxia blocks HIF-1 $\alpha$ hydroxylation and thus pVHL binding to HIF- $1 \alpha$, which will no longer be degraded in the proteasome. Thus, HIF-1 $\alpha$ accumulates in the cytosol, translocates into the nucleus and binds to the HIF-1 $\beta$ subunit to form the active transcription factor [31] (Figure 1a). This transcription factor induces VEGF gene expression, a potent proangiogenic cytokine that induces EC differentiation, triggering the sprouting of ECs to form new vessels (Figure 1b). The VEGF gene has a hypoxia response element (HRE) within its promoter and an enhancer sequence to which HIF-1 binds once inside the nucleus and induces VEGF expression after hypoxia $[32,33]$. Thus, HIF-1 belongs to the transcriptional complex that regulates hypoxia-induced VEGF expression, together with other transcription factors identified described later [34].

Fibroblast growth factors (FGFs), particularly FGF1 and FGF2, are also potent proangiogenic factors. FGFs stimulate new blood vessel formation by driving EC proliferation and migration and also promoting extracellular matrix degradation and pericyte recruitment [35]. Both FGF and VEGF families act synergistically to promote neovascularization because FGF2 upregulates the expression of VEGFR and VEGF in ECs. VEGF upregulates the expression of FGF2. Moreover, FGF2 requires VEGFR1 to exert its capacity of enhancing EC organization [36]. 


\section{Sprouting and anastomosis}

In response to angiogenic stimuli, ECs change their phenotype and bud to form a branch sprout in a process called sprouting. Vessel exposure to proangiogenic signals such as VEGF leads to the acquisition by a fraction of ECs of the commonly known tip cell phenotype, which is characterized by the formation of specialized structures, such as filopodia with migratory capacity and is responsible for sprout guidance. Neighboring cells remain attached to this tip cell and undergo proliferation behind it to form a stalk, in a precisely regulated molecular process in which the Notch/Dll4 pathway plays a prominent role. Stalk cells are also responsible for forming a lumen connected to the lumen of the parent vessel [37-40]. Growth of the sprout towards the stimulus requires EC migration, invasiveness and proliferation. Tip cells respond to a gradient of chemokines, mainly VEGF-A, which determine its migration direction (Figure 2a). It is unclear whether tip cells migrate before stalk cell proliferation and formation of the tube, or whether stalk cell proliferation push the tip cells forward [37]. Sprouting also requires the local degradation and new synthesis of the surrounding basement membrane, mediated by matrix metalloproteinases such as the MT1-MMP family. ECs themselves mediate extracellular matrix (ECM) cleavage, which entails soluble factor release, during the angiogenic response [3].

Endothelial progenitor cells (EPCs) differentiated from hemangioblasts (multipotent precursor cells that can differentiate into both hematopoietic and ECs) were believed to be involved only in vasculogenesis, and embryonic mesodermal cells in situ differentiate into angioblasts that form the primary capillary plexus of the embryo. However, they also play a role in vascularization in the adult $[41,42]$ by both generating a sprout on their own 'postnatal or adult vasculogenesis' - or stimulating mature ECs to undergo sprouting $[37,43]$. The involvement of EPCs in neovascularization has been shown to be essential for ischemic disease recovery or in vascularization after stroke [44-46].

After sprout elongation towards the angiogenic stimulus, tip cells can meet other tip cells belonging to other sprouts of different origin. Anastomosis of both sprouts leads to the formation of an entire new capillary that can undergo maturation $[47,48]$.

\section{Endothelial cells drive and mural cells polish angiogenesis}

Mural cells have been demonstrated to be essential for angiogenesis, the structural integrity of the microvasculature and blood flow regulation, as they contribute to the formation 
of mature capillaries and pre-capillary arterioles. The interaction and interplay between ECs and mural cells plays a pivotal role in vascular biology, including the control of lumen and tube formation, neovessel stability and the migration, proliferation, differentiation and survival of both cell types. In this regard, the recruitment of pericytes and VSMCs along the endothelial tube networks represents a critical event controlling capillary remodeling, maturation and stabilization [49] (igure 3). Furthermore, mural cell and EC co-assembly leads to vascular basement membrane deposition and tube stabilization in 3D matrices [50].

Several adhesion receptors and signaling pathways have been reported to be involved in the interaction between ECs and mural cells. Growing vascular sprouts generate a concentration gradient of platelet-derived growth factor-B (PDGF-B). High levels of PDGF-B produced by tip cells promote the recruitment of mural cells expressing the PDGF receptor $\beta$ (PDGFR- $\beta$ ), stabilizing the growing vessels [37, 51]. In addition, co-cultured VSMCs enhance EC adhesion through activation of paxillin and ERK [52]. Moreover, pericyte-EC interactions depend on numerous direct contacts such as peg-socket contacts and adhesion plaques, which involve vascular endothelial cadherin (VE-cadherin) trafficking [53].

Mural and endothelial cells express several members of the integrin adhesion family of proteins, which are involved in the cell-cell and cell-matrix adhesion processes required for angiogenesis and vessel maturation [54]. A multiprotein complex involving integrin $\alpha_{v} \beta_{8}$ regulates vascular stability, angiogenesis and EC proliferation in the developing embryo [55]. In addition, $\beta_{1}$ integrin family members, including the fibronectin receptor $\alpha_{5} \beta_{1}$, are major determinants of the mural cell phenotype, controlling mural cell adhesion and spreading and blood vessel wall stability [56]. Interestingly, integrins can be activated by proangiogenic chemokines such as CXCL12, triggering EC and leukocyte spreading and migration in an integrin-dependent manner [27, 57-59]. Moreover, CXCL12, which is upregulated by hypoxia [60], increases PDGF-B expression by ECs and promotes the differentiation and recruitment of pericytes and vascular remodeling [61], as well as myogenic differentiation [62]. Furthermore, CXCL12-induced expression of PDGF-B is in turn a potent activator of integrins [63]. However, despite the emerging relevant role of integrins as cell adhesion receptors in vascular biology [64-66], their involvement in the interaction between ECs and mural cells remains largely unexplored.

\section{Vascular remodeling}


Vascular remodeling is an active process of structural alterations and arrangement of blood vessels that involves cell differentiation, proliferation, migration, death and ECM production. As described above, vascular remodeling after artery occlusion is a major process involved in organ reperfusion and includes at least two different processes that are often confused with one another: collateral growth and arteriogenesis.

Collateral growth is a vessel remodeling process with major importance for the restoration of organ perfusion after an arterial occlusion. It consists of the remodeling of pre-existing arterio-arterial anastomosis with a very low flow to produce high capacity conductance arteries that provide most of the needs of the ischemic tissue for oxygen and nutrients. These arteries enlarge after femoral occlusion, and it is widely accepted that the number of preexisting collaterals does not increase after arterial occlusion, not even after maximal stimulation by increased shear stress [2]. Moreover, some authors postulate that collaterals can provide sufficient blood flow to substantially diminish ischemic tissue injury after sudden arterial obstruction $[67,68]$ and that post-ischemic reperfusion can be achieved without any other associated processes such as angiogenesis or arteriogenesis [69].

However, long-term ischemia produces necrosis and vascular network regression. Consequently, even if blood flow is restored by collateral growth, a new expanded vascular network is required for the appropriate delivery of blood to all cells of these tissues. This phenomena, which is also called neovascularization, is often considered synonymous with angiogenesis, but it involves much more extensive sequences of temporally controlled vascular processes, beginning with angiogenesis and the ensuing formation of a new, larger functional circulatory network. During this process, neovessels remodel via vascular cell differentiation and incorporation of perivascular cells into the newly formed vessel walls, resulting in the appropriate density and distribution of arterioles, venules and capillaries. Finally, the new vascular network matures and remodels into a more efficient perfusion circuit that meets the tissue perfusion needs and functions. This process of transformation from a capillary into a mature artery is called arteriogenesis, and this is the term that we will use in this review. It should be noted that the term arteriogenesis is also used by many researchers to describe collateral growth [69].

The mechanisms and signals for mural cell recruitment to newly formed vessels have been described in a previous section. However, vascular wall development is dependent on other mechanisms that are common to arteriogenesis and collateral growth. The major inducer of 
this process is shear stress. In the first scenario, transmural pressure-induced stretch secondary to intravascular blood pressure contributes to vessel wall muscularization in arteriogenesis [70]. Moreover, it has been demonstrated that collateral growth is not stimulated by ischemia but by deformation of the endothelial cells through increased pulsatile fluid shear stress (FSS) caused by the pressure gradient created between the high pressure in pre-occlusive regions and the low pressure in post-occlusive areas connected by these collaterals $[6,71]$. ECs exposed to prolonged laminar shear stress undergo configurational changes in surface adhesion receptors (including selectins and integrins). These changes result in cytoskeletal remodeling and subsequent activation of signal transduction pathways, ultimately leading to an anti-apoptotic state and increased release of the vasodilator NO by activation and expression of all NOS isoforms (eNOS, iNOS and nNOS) [72, 73]. NO plays a major role in stimulating arteriogenesis, as its inhibition markedly reduces the effects of increased FSS, whereas all NOS isoforms are significantly upregulated both at the transcriptional and at the translational level [73]. Deletion of both eNOS and iNOS leads to complete loss of collateral vessel remodeling upon femoral arterial occlusion $[74,75]$. Moreover, increased shear stress mediates endothelium quiescence by inhibiting EC proliferation and promotes pericyte recruitment [76]. Elevations in shear stress also lead to the production of MCP-1 in the endothelium and the smooth muscle layer, which leads to a cascade inflammatory response with infiltrating leukocyte populations. MCP-1 attracts monocytes and T-cells into the vessels during remodeling, a process that is favored by the marked increase in the expression of adhesion molecules on the endothelial surface of growing vessels. The monocytes that have accumulated into the collateral walls transform into macrophages, and resident macrophages become also activated. Mononuclear and activated VSMCs produce proteases and growth factors to digest the extracellular scaffold, allowing VSMC motility and providing space for the new cells. In addition to its participation in the digestion of the extracellular scaffold, monocytes produce paracrine growth factors

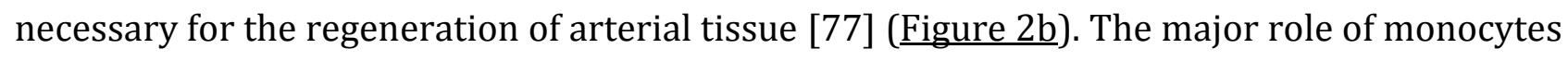
in arteriogenesis has been demonstrated by many experimental approaches, showing that the administration of MCP-1 or other substances favoring monocyte recruitment, or overtransfusion with monocytes, markedly stimulated collateral growth, whereas reduction of the blood monocyte count or deletion of the genes for MCP-1 or for the MCP-1 receptor (CCR2) was associated with markedly reduced collateral growth [2].

In addition to monocytes, other leukocytes also contribute to arteriogenesis, mainly $\mathrm{T}$ - 
lymphocytes and NK-cells [78, 79]. Furthermore, EPCs have also been reported to be recruited by growing vessels, changing their phenotype into ECs or VSMCs $[80,81]$.

ECs play also an important role in mural cell recruitment, but their role has been described in a previous section (Endothelial cells drive and mural cells polish angiogenesis).

\section{A KEY ROLE OF ENDOGLIN IN ANGIOGENESIS AND VASCULAR REMODELING}

\section{What is endoglin?}

Endoglin (Eng, CD105) is a type I homodimeric membrane glycoprotein that acts as an auxiliary receptor in the receptor complex for several members of the TGF- $\beta$ family of cytokines. The TGF- $\beta$ family comprises not only TGF- $\beta$ isoforms but also bone morphogenetic proteins (BMPs), activins, inhibins, growth and differentiation factors (GDFs), among others. Endoglin interacts with type I and type II TGF- $\beta$ receptors (T $\beta$ RI and T $\beta R I I$, respectively) to form the signaling TGF- $\beta$ receptor complex [82]. Endoglin is highly involved in endothelium function and vascular homeostasis; it plays a major role in angiogenesis [83].

The predominant full-length endoglin isoform, L-endoglin, is formed by two 90-kDa monomers that are linked to one another by disulfide bonds. Structurally, the extracellular region of endoglin contains two distinct domains: (i) a zona pellucida (ZP) juxtamembrane domain that in human endoglin displays the prototypic Arg-Gly-Asp (RGD) motif involved in integrin-based interactions [84, 85], which has a mouse homologous sequence, TDD [27]; and (ii) the $\mathrm{NH}_{2}$-terminal orphan domain involved in binding to BMP9, another member of the TGF- $\beta$ family [85-87]. In addition to having a single transmembrane region, endoglin has a constitutively phosphorylated short intracellular domain, in which a PDZ binding domain plays a relevant role $[84,88,89]$. In human and mouse endoglin genes, the last intron can be retained as a result of an alternative splicing event. This intron retention leads to the generation of a premature stop codon in the endoglin mRNA, which is translated into a shorter protein named S-endoglin $[90,91]$. In humans, S-endoglin has an intracellular domain that is 33 residues shorter than L-endoglin and lacks the PDZ binding motif (Figure 5). One of the splicing factors involved in this intron retention process is serine-arginine splicing factor 1 (SRSF1 or ASF/SF2) [92]. Notably, ASF/SF2 is also involved in the selection of the splice site that yields proangiogenic VEGF isoforms, a process that is inhibited by TGF- $\beta$ [90, 93]. Interestingly, S-endoglin expression is induced during senescence in ECs [93-95] and macrophages [96]. It is interesting that post-ischemic reperfusion is impaired in 
senescent individuals [67]. Different cell properties observed upon L-endoglin or S-endoglin expression suggest that the intracellular domain is essential for the modulation of several cellular processes $[95,97]$. Notably, it can be postulated that there should be no differences in those events that are mediated or promoted by the extracellular domain of endoglin between isoforms because this domain is identical in both protein variants. Unless stated otherwise in this review, the reported endoglin data correspond to the predominant isoform L-endoglin.

A soluble form of endoglin, sEng, is released upon metalloprotease cleavage of any of the membrane isoforms [98, 99]. Increased sEng shedding has been reported to play a role in vascular pathologies such as pulmonary hypertension and preeclampsia $[100,101]$ and in several cancers [102]. The involvement of sEng in modulating angiogenic processes has also been suggested, i.e., impaired neovascularization in preeclampsia [103]. Moreover, sEng has been shown to inhibit capillary tube formation in vitro and to induce vascular leakage in vivo [104]. More recently, sEng has been demonstrated to impair angiogenesis in vivo [86]. Among the mechanisms of action proposed for sEng are sequestering of angiogenic ligands such as TGF- $\beta$ or BMPs, or blocking the binding of full-length endoglin to the receptor complex. As a result, TGF- $\beta$ family members cannot properly bind their receptors or transduce their angiogenic signal.

\section{Evidence for the role of endoglin in angiogenesis and vascular remodeling}

Endoglin is upregulated in tissues undergoing angiogenesis

Endoglin is mainly expressed in endothelium, where its gene promoter displays elevated activity compared with the other cell types [105]. Endoglin expression is a stronger marker of ECs than other markers such as VEGFR2, adhesion molecules (ICAM, PECAM, VCAM) or von Willebrand Factor (vWF) [106]. In addition to endothelium, endoglin is highly expressed in placental syncytiotrophoblasts [107] and, at lower levels, in activated blood monocytes [108], VSMCs [109], pericytes [110] and other different tissues, as previously reviewed [14].

Endoglin expression is upregulated in active endothelium undergoing angiogenesis. Specifically, endoglin expression increases in endothelium at the angiogenic edge, where vessel sprouting occurs [17]. Tissue immunostaining in different studies has revealed that several solid tumors and leukemic bone marrow undergoing active angiogenesis, present strong labeling for endoglin in the endothelium of tumor vessels [15, 111-113] and weaker staining in non-malignant tissues. This increased expression of endoglin in the tumor 
endothelium correlates with a higher expression level of cellular proliferation markers [114]. Membrane-bound endoglin levels are elevated after myocardial infarction, and the correct neovascularization and recovery of the infarcted zone depends on adequate endoglin expression [20]. Moreover, endoglin is also highly expressed in blood vessels upon vascular injury in humans and mice [115], after oxygen-induced angiogenesis in the retina $[17,18]$ and during pathological angiogenesis in chronic colitis [116].

In vitro studies have shown that human umbilical vein endothelial cells (HUVECs) with low levels of endoglin are mainly quiescent, whereas HUVECs with upregulated endoglin expression are actively proliferating cells [111].

\section{Endoglin expression modifies angiogenesis and vascular remodeling}

Endoglin null mice die around mid-gestation (E10-11.5) from defective yolk sac vasculogenesis and heart growth $[117,118]$. The TGF- $\beta 1$ and TGF- $\beta$ receptors ALK1 and T $\beta R I I$ null mice also die around mid-gestation (E10-13.5) from similar vascular alterations, which involve not only the endothelium but also a reduction of VSMC numbers and recruitment to the vasculature plexus in the yolk sac and embryo [119-121].

Hereditary hemorrhagic telangiectasia type 1 (HHT1), also known as Rendu-Osler-Weber syndrome, is a vascular disease caused by mutations in the endoglin gene that leads to endoglin haploinsufficiency. It is characterized by an impaired angiogenic process that leads to arteriovenous malformations (AVMs), fragile vessel walls, and pulmonary, liver and cerebrovascular problems due to vascular defects $[122,123]$. Endoglin itself is responsible for endothelium integrity because an induced lack of endoglin leads to the apparition of AVMs when a pro-angiogenic or an inflammatory stimulus occurs in mice with endothelial-specific loss of endoglin (Eng-iKO $)$ [124, 125]. Moreover, recent evidence has demonstrated that endoglin deficiency inhibits shear fluid stress blockage of EC proliferation together with pericyte recruitment [76].

Endoglin heterozygous (Eng $\left.{ }^{+/}\right)$mice -which have endoglin protein levels that are reduced by 50\%- are usually used as an animal model to study HHT1 [126]. These haploinsufficient mice display delayed reperfusion and impaired angiogenesis following hind limb ischemia induced by femoral ligation [19]. Moreover, the tumor growth rate and tumor capillary density are reduced in Eng ${ }^{+/-}$compared with wild-type mice [21]. Furthermore, Jerkic et al demonstrated that mouse aortic endothelial cells (MAECs) from these mice showed reduced VEGF 
production and decreased proliferation and migration rates, which are essential processes for sprouting and initial steps of angiogenesis [19]. Another study showed that Eng ${ }^{+/-}$mice display impaired revascularization after myocardial infarction [20]. In addition, Eng ${ }^{+/-}$mice develop smaller collateral arteries in response to shear stress after hind limb ischemia, whereas the angiogenic response to ischemia-related hypoxia generates larger but dysplastic capillaries in these mice. These two effects explain the delayed blood flow recovery after induction of hind limb ischemia [22]. Retinal neovascularization in Eng ${ }^{+/-}$mice after oxygeninduced ischemic retinopathy (OIR) revealed markedly impaired angiogenesis in the retina, with little or no angiogenic tuft formation [18]. However, a larger number of proliferative cells have been reported within the vasculature of normal retinas from $\mathrm{Eng}^{+/}$- mice at different stages of development, as compared with wild type mice. It has also been reported that retinas from Eng//- pups under normal conditions show enhanced branching during sprouting [127], suggesting that increased proliferation does not always lead to increased effective angiogenesis.

In vitro studies of the effect of different levels of endoglin in EC proliferation have produced discordant results. Some studies have reported that a lack of endoglin increases the proliferative response of ECs in culture [128-130]. Moreover, treatment with endoglin antisense oligonucleotides leads to reduced protein levels and an enhanced antiproliferative response to TGF- $\beta$ [131]. At variance with these results, cultured Eng ${ }^{+/-}$ECs present smaller growth rates than $\mathrm{Eng}^{+/+}$ECs $[19,132]$, suggesting a pro-proliferative effect of endoglin. Moreover, an opposite endoglin-mediated cell responses to TGF- $\beta$, such as Smad activation and proliferative and migratory activities, has also been reported in different biological settings [12, 83, 132-136]. The different results observed among these reports can be explained by the distinct cell types (established EC lines, primary cultures of ECs, ECs from veins or arteries, ECs from micro or macrovascular endothelium), cell differentiation stages (from embryos or adults) and experimental conditions (different media and variable TGF- $\beta$ concentrations) used in every study. For example, experimental evidence supports the ability of endoglin to modulate TGF- $\beta 1$ signaling in endothelium and, subsequently, angiogenesis. TGF- $\beta 1$ has been largely considered to have an anti-proliferative effect over ECs [137], while a dose-dependent effect of TGF- $\beta 1$ in angiogenesis and cell proliferation has also been described in several reports [138-140]. When endoglin expression is blocked in HUVECs, in vitro EC tube formation upon TGF- $\beta 1$ stimulation is impaired [131]. By contrast, other studies have suggested that endoglin counteracts TGF- $\beta 1$-induced inhibition of angiogenesis-related responses in vitro. Thus, endoglin has been considered to promote EC proliferation in 
several studies. Furthermore, endoglin counteracts the inhibition of EC proliferation caused by high doses of TGF- $\beta$, while it promotes proliferation induced by low doses of TGF- $\beta$. This pro-proliferative effect of endoglin appears to be mediated by the TGF- $\beta /$ ALK1/ALK5 signaling pathway, whereas the loss of endoglin leads to TGF- $\beta$ signaling through the ALK5 pathway, which has an antiproliferative effect because ALK5 knock-down rescues EC proliferation in the absence of endoglin [140]. In a rat myoblast model, TGF- $\beta$ showed an antiproliferative effect both at low and high doses, and the effect at lower doses was rescued by overexpression of endoglin [139]. Conversely, low doses of TGF- $\beta$ have shown an endoglinmediated antiproliferative effect in ECs isolated from the retina, as this effect was abrogated in ECs from Eng+/- retinas [18]. These divergent results could again be explained based on the different types of cells used and their different origins. This conclusion prompts the necessity for further studies to elucidate the physiological role of TGF- $\beta$ in EC proliferation and angiogenesis, as well as the function of endoglin in modulating this process.

Moreover, BMPs, which belong to TGF- $\beta$ cytokine family, are also involved in the regulation of angiogenesis. BMP2, 4, 6 and 7 have been reported to increase VEGF levels, to enhance capillary tube formation, to promote the proliferation and migration of ECs during the activation phase of angiogenesis, and to regulate the physiology of mural cells during the maturation phase $[141,142]$. In contrast, antiangiogenic responses have also been reported in other studies, again depending on the BMP dose and cellular context $[143,144]$. Contradictory results regarding BMP9 and BMP10 in angiogenesis have also been described. Although an antiangiogenic effect of BMP9 was first described [145-147], it has been accepted that it occurs as a consequence of high BMP9 doses, while lower doses promote angiogenesis via ALK1 signaling $[148,149]$. Additionally, endoglin interacts with BMP2 and BMP7 when other members of the receptor complex are present, and it can bind to BMP9 on its own [86, 87, 150]. Thus, endoglin may play a role in BMP signaling during angiogenesis. In support of this view, endoglin is necessary for BMP9 signaling in ECs involved in angiogenesis [151], and the blockade of BMP9 binding to ALK1 prevents endoglin binding to ALK1 and the subsequent angiogenic response [149].

Therefore, based on the current literature, endoglin appears to be an essential modulator of the cellular response to TGF- $\beta$ and BMP cytokines. Moreover, its potential therapeutic implications have recently been reviewed by Jonker [152].

\section{How does endoglin orchestrate reperfusion?}


Although it is widely recognized that endoglin is needed for proper reperfusion responses, the questions of where and how endoglin function to coordinate these complex responses remain to be answered. In this review, we intend to provide evidence of the involvement of endoglin in several angiogenic processes, which may help us understand why endoglin is crucial for accurate reperfusion. A summary of this evidence is listed in Table 1.

\section{Endoglin is involved in the response to hypoxia}

Both TGF- $\beta 1$ and endoglin genes can be regulated by hypoxia due to the presence of HREs in their gene promoters [153]. HREs are composite regulatory elements comprising a conserved HIF-binding sequence and a highly variable flanking sequence that modulates the transcriptional response. Thus, endoglin expression is upregulated under hypoxia conditions in human ECs, monocytic cell lines and epithelial cells $[83,153]$. Furthermore, TGF- $\beta 1$ itself increases endoglin expression [105, 133, 153-157]. These results suggest that gene expression of endoglin can be regulated by a synergistic cooperation between hypoxia and TGF- $\beta 1$ due to the presence of HREs and Smad binding motifs in its gene promoter region.

In addition, TGF- $\beta 1$ treatment further increases HIF- $1 \alpha$ expression in endothelial cells under both hypoxic and normoxic conditions. TGF- $\beta 1$ does not increase HIF-1 $\alpha$ mRNA levels nor decrease the rate of protein degradation, suggesting that it enhances normoxic HIF-1 $\alpha$ translation [158]. However, hypoxia can also induce endoglin expression via other mechanisms, including MAP kinase pathway activation [159]. It should be noted that in the presence of both hypoxia and TGF- $\beta$, endoglin is able to prevent EC apoptotic death [155].

As described above, reduced retinal neovascularization has recently been reported in Eng $/$ mice after OIR due to an impaired angiogenic response of ECs [18]. However, endoglin can function as a protective factor against endothelial apoptosis because endoglin inhibition enhances hypoxia and TGF- $\beta$-induced endothelial apoptosis [155]. Therefore, the expression of endoglin increases after hypoxia, and endoglin seems to be essential to modulate angiogenesis in response to this hypoxic environment.

\section{Endoglin modulates the production of angiogenic soluble factors}

VEGF and NO are two main endothelial factors that are directly involved in angiogenesis and vascular remodeling. There are several lines of experimental evidence indicating that NO is a 
key component of the functional regulation of VEGF in the endothelium. NO mediates VEGFinduced HUVEC proliferation and tube organization of ECs in 3D culture. Moreover, EC exposure to VEGF increases both the endothelial NO synthase (eNOS) levels and NO production, whereas inhibitors of eNOS reduce VEGF-induced angiogenesis [160]. Furthermore, NO production is directly regulated by oxygen tension and is impaired under hypoxic conditions, and, in turn, NO induces HIF-1 $\alpha$ degradation [161]. Interestingly, both NO and VEGF have been related to the function of endoglin.

Our group has previously demonstrated that endoglin haploinsufficiency impairs NO production [162] due to reduced eNOS expression [19]. These results have been confirmed more recently in ECs from Eng ${ }^{+/-}$mouse retina [18]. Furthermore, eNOS expression is upregulated by endoglin via Smad2 signaling [163]. More recently, reduced levels of eNOS have been described in EPCs from HHT patients [164]. Both, endoglin and eNOS proteins colocalize and interact with one another within caveolae. Endoglin increases eNOS stability and is necessary for eNOS binding to its cofactor Hsp90. Therefore, eNOS is uncoupled in Eng ${ }^{+/}$ cells and leads to increased ROS release and decreased NO production [165]. Like eNOS, Cav-1 and Hsp90, which can associate with endoglin, are located on the cytosolic side of plasma membrane, and it could be argued that their interaction with endoglin occurs through its intracellular domain. Consequently, this cytoplasmic interaction can be predicted to be altered or even abrogated in the case of the minor S-endoglin isoform.

A link between endoglin expression and VEGF-induced angiogenesis has been reported, although the underlying mechanisms have not been fully elucidated. Aortic ECs isolated from Eng ${ }^{+/-}$mice produce less VEGF than control cells [19], whereas retinal ECs isolated from these haploinsufficient mice produce larger amounts of VEGF [18]. These differences can be explained by the different origin of the ECs: macro versus microvasculature. Moreover, HHT1 patients, with mutations in the endoglin gene and vascular defects present increased VEGF plasma levels [166, 167]. BMP9 has been shown to enhance endoglin expression together with the blockade of VEGF-induced angiogenesis ex vivo [146]. Conversely, it has been shown that endoglin is required for VEGF-induced angiogenesis, although endoglin deficiency does not affect VEGF signaling [168]. However, anti-VEGF treatment in pancreatic carcinoma induces an increase in HIF-1 $\alpha$ and in endoglin expression [169]. Moreover, endoglin and VEGF may be involved in endothelium stability, as will be discussed below.

In summary, endoglin, NO and VEGF, all of which have proangiogenic activity, are in equilibrium because their levels are mutually regulated and their mechanisms of action are 
interconnected. Further studies are required to fully understand the relationship among endoglin, NO and VEGF.

\section{Endoglin in the recruitment and differentiation of endothelial progenitors}

Populations of bone marrow-derived EPCs are present in the adult and are mobilized into the circulation by stimuli such as estrogen and VEGF [170]. Two populations have been differentially characterized from circulating endothelial precursors. On the one hand, early EPCs exhibit a hematopoietic profile, with a genomic fingerprint that resembles monocytes. On the other hand, blood outgrowth endothelial cells (BOECs), also known as endothelial colony forming cells (ECPCs) are considered late EPCs and present an endothelial-like genomic profile. BOECs have been grown in vitro in several works to study angiogenesis because they possess the ability to form angiogenic sprouts in vitro [171-174]. Moreover, a fraction of ECs within the vascular wall are the so-called "resident precursor cells" [175]. EPCs, both circulating and resident, can then differentiate into mature ECs that line the lumen of blood vessels and/or release growth factors that act in a paracrine manner to support the endothelium. EPCs are thus thought to function in angiogenesis and as a reservoir for the replacement of dysfunctional or senescent ECs to maintain the existing vessel walls $[176,177]$. In addition, the levels of circulating EPCs are increased after vascular insult and, in several diseases, related to post-injury regeneration of the vasculature [178-181].

Endoglin is considered to be expressed only by mature ECs $[175,182]$, but it can be expressed by EPCs after VEGF-driven differentiation into ECs [183]. Investigations of vasculogenesis -or vascularization of the embryo- in Eng ${ }^{+/}$mice have revealed enhanced ectopic CD34 expression in embryo cardinal veins. Because CD34 is considered to be an arterial marker, this finding suggests a loss of vessel identity due to deficient precursor cell homing in mice that are heterozygous for endoglin [184]. Characterization of BOECs from HHT1 patients has revealed an altered morphology, a disorganized F-actin cytoskeleton, a decreased capacity to form capillary-like structures and, therefore, a reduced angiogenic potential [185]. BOECs from HHT-1 patients showed a downregulation of the expression of genes involved in angiogenesis, cell adhesion, cytoskeleton, migration, and cell cycle and survival, such as WASL, eNOS, PCDH12 (VE-cadherin 2), PECAM-1, ANGPT-2, CCNB2 (cyclin B2), and CDC25B (cell division cycle 25B). In addition, these cells presented reduced adhesion, migration and proliferation [186]. Recently, a reduced ability of these circulating HHT1 cells to differentiate has been reported, revealing a reduced binding to lectin or acLDL, characteristics of mature 
ECs, and an attenuated mobilization towards strong angiogenic stimuli such as VEGF or CXCL12 [164]. Taken together, these results suggest a compromised function of EPCs in angiogenesis in the presence of reduced cellular levels of endoglin.

\section{Endoglin modulation of endothelial cell barrier integrity}

VEGF is a major inducer of angiogenesis and increased vascular permeability, leading to increased vessel leakage $[187,188]$. Interestingly, endoglin haploinsufficiency in Eng+/- mice is associated with weakness of the endothelial barrier and with an increased metastatic rate when tumors are produced in these mice [16]. Such increased vascular permeability was also observed in the distal colon of $\mathrm{Eng}^{+/-}$mice and was related to enhanced levels of VEGF [189]. Of note, high levels of VEGF production have also been observed in ECs isolated from Eng ${ }^{+-}$ mouse retinas [18]. Recently, vascular permeability, measured by the passage of fluorescent dextran through EC monolayers, was shown to be increased in Eng ${ }^{-/}$and $\mathrm{Eng}^{+/-}$ECs compared with control ECs. This hyperpermeability of endoglin-deficient EC monolayers is associated with a decrease in VE-cadherin expression and constitutive activation of RhoA, and it was further increased by TGF- $\beta 1$ or VEGF [190]. In this context, the potential involvement of VEcadherin deserves further analysis.

VE-cadherin expression is related to a quiescent state of the endothelium, when stable cellcell interactions or adherens junctions are firmly established. VE-cadherin exerts not only a structural function by joining cells through homotypic interactions, but it also inhibits angiogenic responses such as VEGFR2 phosphorylation and signaling, thus blocking the VEGF proliferative signal in the endothelium [191]. Conversely, VEGF can induce VE-cadherin internalization and subsequent disruption of cell-cell interactions of ECs in a $\beta$-arrestindependent manner [192], a process that can be modulated by endoglin due to its ability to interact with both VE-cadherin and $\beta$-arrestin, as well as the above described involvement in some responses to VEGF. Furthermore, endoglin haploinsufficiency diminishes cell-cell junctions by downregulating VE-cadherin, as well as PECAM, $\beta$-catenin and ZO-1 expression. Interestingly, VE-cadherin improves TGF- $\beta$ receptor complex assembly at cell-cell contacts by interacting with T $\beta R I I, T \beta R I$ (ALK1 and ALK5) and endoglin. Although the interaction between VE-cadherin and endoglin is not necessary for the formation of the TGF- $\beta$ receptor complex, it may act as a modulator of membrane protein assembly and the downstream signal transduction [18]. The same authors also reported that TGF- $\beta$-induced Smad2/3 activation in endoglin-deficient ECs is more persistent than Smad1 phosphorylation, in agreement with a 
previous report [193], due, at least in part, to the VE-cadherin-related effect. Moreover, VEcadherin null cells present a lack of TGF- $\beta$ inhibition of proliferation [194].

\section{Endoglin regulation of focal adhesions during EC migration}

Endoglin localizes at focal adhesions and regulates cell migration [195] due, at least in part, to its capacity to bind zyxin, a protein that is concentrated at these zones and along the actin cytoskeleton [196]. Moreover, the presence of endoglin promotes the change in localization of zyxin related protein 1 (ZRP-1) from focal adhesions to actin fibrillar structures, which participates in reshaping the actin cytoskeleton [197]. Therefore, a reduction or increase in endoglin levels can lead to alterations in cellular morphology and cell motility. Because of the cytoplasmic localization of zyxin and ZRP-1, the intracellular domain of endoglin emerges as a key modulator of cytoskeletal organization and cell migration.

In support of this view, BOECs from HHT1 patients exhibit an altered morphology together with F-actin cytoskeleton disorganization and reduced migration [185, 186]. More recently, studies of cultured EPCs from HHT1 patients revealed an impaired mobilization of these cells towards proangiogenic stimuli such as VEGF and CXCL12, as compared with cells from healthy donors [164]. Furthermore, endoglin neutralization with the monoclonal antibody TRC105 decreases HUVEC migration and capillary-like structure formation, most likely by inhibiting the BMP9-Smad1/5/8 signaling pathway [198]. In contrast, overexpression of endoglin in various non-endothelial cell types causes diminished migration rates [196]. Moreover, either L-endoglin or S-endoglin isoform overexpression in prostate cancer cells results in reduced migration [195]. This effect has been confirmed in endoglin null murine embryonic endothelial cells (MEECs), resulting in increased migration, whereas the rescue of endoglin expression reduced migration to rates similar to those of wild type cells. This effect on EC migration is dependent on the phosphorylation of Ser646 in endoglin by ALK5 [193, 199].

\section{Endoglin modulation of TGF- $\beta$ signaling in angiogenesis}

TGF- $\beta 1$ initiates signaling in ECs first by ligand binding to T $\beta$ RII, which triggers the recruitment of T $\beta R I$ and either ALK5 or the predominantly endothelial ALK1. Both T $\beta$ RI and T $\beta$ RII dimerize prior to assembly into the TGF- $\beta$ receptor complex, forming not only homodimers but also heterodimers. It is widely accepted that stimulation of the T $\beta$ RII/ALK5 signaling complex subsequently activates the phosphorylation of Smad2/3. Once 
phosphorylated, Smad2/3 binds to Smad4, and this heteromeric complex translocates into the nucleus where it functions as a transcription factor, increasing the expression of the ECM components, PAI-1 and PDGF-B, among other genes, while inhibiting the proliferation and migration of ECs [200]. In addition, there is another TGF- $\beta$ signaling route that involves the TßRII/ALK1 complex to promote the phosphorylation of Smad1/5/8. In turn, phosphorylated Smad1/5/8 binds to Smad4 and the resulting complex, with proangiogenic transcriptional activity, and promotes endothelial proliferation and migration as well as ECM degradation. Furthermore, the Smad1/5/8 pathway negatively regulates the expression of PAI-1, an ALK5 target gene [193, 201-205]. This dual and opposite effect of ALK1/ALK5 remains controversial. For example, TGF- $\beta$ signaling inhibition decreases retinal perfusion and impairs endothelial barrier function in mice [206], while other authors have reported a TGF- $\beta$ mediated inhibition of proangiogenic molecules [207] or a proangiogenic effect of TGF- $\beta$ blockade [208]. Moreover, Smad1/5/8-mediated blockade of EC migration [209], and the inhibition of tip cell differentiation -with a migratory phenotype- by BMP9 signaling through ALK1-Smad1/5/8 have been described [40]. We should take into account, as discussed above, that different TGF- $\beta$ concentrations may exert opposite effects on ECs, further complicating the dissection of the precise effect of endoglin.

Endoglin binds to T $\beta R I$ (ALK1 or ALK5) and T $\beta$ RII through both its extracellular and cytosolic domains in a ligand dependent manner, and the latter is phosphorylated by both type I and II TGF- $\beta$ receptors [210]. The cytosolic domain of endoglin is phosphorylated at Ser ${ }^{634}$ and Ser635 residues by T $\beta$ RII. Absence of the PDZ domain promotes this phosphorylation, suggesting that proteins that bind to the PDZ domain, usually scaffolding molecules, can interfere with endoglin phosphorylation when bound to its PDZ domain. Moreover, ALK1 phosphorylates endoglin at $\mathrm{Thr}^{640}$ and $\mathrm{Thr}^{654}$ residues, but this process requires previous Ser634 and Ser635 endoglin phosphorylation. Neither and Ser635 nor the PDZ domain interfere with the interaction of endoglin interaction with TßRII, ALK1 or ALK5 receptors [89]. The cytosolic domain of endoglin is also phosphorylated by ALK5 in Ser646 and Ser649, and the loss of this phosphorylation impairs ALK1-induced phosphorylation of endoglin, shedding light on the mechanism responsible for ALK5-dependent ALK1/endoglin signaling [202, 211]. Moreover, the absence of cytosolic Thr residues in an endoglin mutant protein prevents endoglin modulation of ALK1-dependent responses, such as a reduced viability or loss of focal adhesion and adhesive capacity responses in HUVECs [89]. These studies suggest that it is not only the interaction of endoglin with the TGF- $\beta$ receptor complex that modulates the effects of TGF- $\beta$ but also the phosphorylation of its intracellular domain. The cytosolic domain 
of endoglin has been shown to interact with several anchoring proteins, including zyxin, ZRP1, $\beta$-arrestin or GIPC. These interactions modulate several processes that are involved in angiogenesis [197, 212, 213]. S-endoglin lacks the PDZ binding motif as well as the Ser634, Ser635,Ser646, Ser649, Thr ${ }^{640}$ and Thr $^{654}$ residues that are susceptible to phosphorylation [88] (Figure 5). Thus, a differential effect between L-endoglin and S-endoglin is expected, at least in those processes involving the cytosolic domain.

The ability of endoglin to modulate TGF- $\beta$ family signaling through the ALK1/Smad1/5/8 pathway and its therapeutic relevance has recently been reviewed $[152,214]$. It has been proposed that endoglin collaborates with the ALK1 signaling pathway to stimulate the active phases of angiogenesis through Smad1/5/8 activity [193, 215]. However, endoglin deficiency in the endothelium has been shown to reduce the activation not only of Smad1/5 but also of Smad2/3, an effect that is likely due to the reduced levels of T $\beta$ RII [18].

Furthermore, endoglin is believed to promote ALK1-mediated signaling in the presence of BMPs. Both BMP9 and BMP10 have been proposed to have a redundant effect in adult endothelium, and both cytokines can bind to ALK1 with high affinity. Unlike TGF- $\beta$, BMP9 binds to the endoglin orphan domain by itself [87]. BMP9 signals through the endoglin/ALK1 complex, and anti-ALK1 antibodies prevent the formation of the BMP9/ALK1/endoglin complexes and attenuate BMP9-dependent signaling and sprouting [149]. Additionally, endoglin appears to be necessary for BMP9 signaling through ALK1 in HUVECs, in which TGF$\beta$ is unable to activate Smad1/5/8 signaling on its own [151]. Similarly, contradictory findings regarding the effect of BMPs in angiogenesis have been reported. On the one hand, BMP9 signaling via the ALK1-Smad1/5/8 pathway may promote in vitro angiogenesis in human microvascular endothelial cells (HMVECs) and HUVECs. On the other hand, other authors have reported that BMP9, despite signaling via ALK1/endoglin activation, inhibits EC proliferation and migration, promoting the resolution phases of angiogenesis. This duality of the angiogenic effects of BMP9 has been thoroughly reviewed $[143,152]$.

The vast majority of articles concerning to the role of endoglin in TGF- $\beta$ signaling have assessed L-endoglin. To date, the role of the S-endoglin isoform in TGF- $\beta$ /BMP signaling in ECs and in angiogenesis has been poorly addressed. S-endoglin and L-endoglin differentially modulate the ALK5 and ALK1 signaling pathways [95, 97], suggesting that they may contribute to the complex and dual role of TGF- $\beta$ in angiogenesis. Transgenic mice that specifically overexpress human S-endoglin in the endothelium exhibit a deficient angiogenic phenotype that drives a significant delay in tumor growth [91], similar to the effects observed 
in mice lacking L-endoglin $[21,216]$. S-endoglin has been shown to promote TGF- $\beta$ signaling through ALK5, the reporter activity of which is inhibited by TGF- $\beta$ in response to L-endoglin expression [95]. Because endoglin is not able to bind to TGF- $\beta$ by itself, requiring the presence of T $\beta$ RII [139], the effect of S-endoglin on the TGF- $\beta$ signaling may be related to receptor complex sequestering in competition with the long isoform. However, due to the ability of the extracellular domain of endoglin to bind BMP9 on its own, both L and S-endoglin are expected to bind similarly this ligand. Therefore, S-endoglin can sequester not only the complex but also the ligand in the case of BMP9. In this regard, the importance of the L-endoglin/Sendoglin ratio based on a competitive effect between both isoforms for binding to the receptor complex can be postulated. According to this model, overexpression of S-endoglin would decrease the number of L-L endoglin homodimers and increase the frequency of L-S heterodimers, thus changing TGF- $\beta$ signaling from ALK1/Smad1/5/8 to ALK5/Smad2/3. Furthermore, while L-endoglin overexpression decreases collagen I and CTGF expression and increases cell proliferation, S-endoglin overexpression strongly enhances collagen I and CTGF expression and reduces proliferation in rat myoblasts [97]. Taken together these experiments suggest that in contrast to the proangiogenic role of L-endoglin, S-endoglin has an antiangiogenic effect.

Apart from the canonical Smad signaling pathway, TGF- $\beta$ family members modulate other pathways such as Src kinase, ERK1/2, JNK and p38 MAP kinases or the PI3K/Akt route. MAPK activation has been related to enhanced cell survival, migration and capillary network organization, together with disruption of endothelial stability and cell-cell interactions and, thus, vascular permeability $[18,217,218]$. Akt signaling has emerged as a key modulator of in vitro capillary formation by ECs. BMP9 activates PI3K in an endoglin-dependent manner through endoglin PDZ domains by anchoring to the scaffolding protein GIPC that binds PI3K. In turn, Akt activation protects ECs from apoptosis, enhancing sprouting [213]. By contrast, TGF- $\beta$ shows the opposite effect, reducing Akt activation and therefore promoting apoptosis, in an endoglin-dependent manner. Therefore, deficient TGF- $\beta$ signaling could explain recent results showing enhanced activation of Akt, ERK, JNK and p38 in Eng+/- ECs [18]. Conversely, endoglin expression inhibits the ERK signaling pathway [129, 219]. Moreover, endoglinmediated TGF- $\beta$-induced ERK inactivation depends on the interaction between the cytosolic domain of endoglin and $\beta$-arrestin $[212,220]$. These results further suggest that the cytosolic domain of endoglin is essential for proper signaling of the TGF- $\beta$ family of cytokines. 


\section{Endoglin in vascular remodeling}

As above described, some studies have examined the role of endoglin in blood flow recovery after tissue ischemia. We have reported impaired reperfusion and angiogenesis after femoral ligation in Eng ${ }^{+/}$compared with wild type mice [19]. Seghers et al performed a similar experiment a few years later, and they also studied the effect of femoral ischemia on Eng ${ }^{+/}$ mice together with the assessment of collateral growth. Similar to our results, after induction of hind limb ischemia by femoral artery ligation, Eng ${ }^{+/-}$mice exhibited a significant delay in blood flow recovery in the ischemic hind limb compared with control mice. The analysis of collateral artery size revealed significantly smaller collateral arteries in Eng ${ }^{+/-}$mice. MEECs were cultured under conditions of flow to mimic shear stress in vitro, revealing a timedependent increase in endoglin mRNA expression [22]. Collateral formation is a shear stressinduced process that is associated with an increase in endoglin expression. Because endoglindeficient mice present impaired collateral growth, a role for endoglin in this process can be hypothesized. It has recently been demonstrated that activation of endoglin under shear stress mediates vascular quiescence by inhibiting EC proliferation and promoting pericyte recruitment [76]. This interpretation is in agreement with the observation that endoglin is expressed by both ECs and VSMCs, as well as by fibroblasts in the perivascular stroma of arteries [221-223], all of which are involved in collateral growth. Interestingly, shear stress plays a role in the activation of ALK5/TGF- $\beta$ signaling in the endothelium [224].

It should be noted that collateral formation is not always associated with increased endoglin expression. For example, cerebral hypoxia triggers active remodeling of small vessels into larger ones, but surprisingly, hypoxia produces a marked reduction of endoglin expression in brain endothelial cells (BECs) within actively remodeling arterioles [225], and these remodeling BECs display an angiogenic switch in $\beta_{1}$ integrins from $\alpha_{6}$ to $\alpha_{5}$, which has been previously described in angiogenesis [226]. In in vitro experiments, TGF- $\beta 1$ promotes the angiogenic switch of BEC $\beta_{1}$ integrins. Taken together, these data suggest that BECs in remodeling brain collaterals show reduced endoglin expression, thereby altering TGF- $\beta 1$ signaling to promote an angiogenic switch in $\beta_{1}$ integrins, facilitating vascular remodeling and the formation of new arteries that increase the supply of blood to the ischemic areas [225]. These findings also suggest that the precise role of endoglin in vascular remodeling depends on the tissue in which the ischemia is produced.

\section{Endoglin regulation of mural and mononuclear cell recruitment}


Mural cell recruitment is a key process in both arteriogenesis and collateral growth. Endoglin is highly expressed by ECs during arteriogenic processes at the same time as mural cell recruitment to vessels [227]. Several lines of experimental evidence support the involvement of endoglin in mural cell recruitment to EC tubes. First, mice lacking endoglin (Eng $/$ ) die by gestational day 11.5 from defective vascular development, although the vasculogenesis process remains unaffected $[117,118,126]$. Interestingly, loss of endoglin in these Eng $/$ mice causes poor vascular smooth muscle development and arrested vascular remodeling [117]. It has also been reported that in yolk sacs from endoglin KO mice, $\alpha$ SMA levels are remarkably low because of the failure of VSMCs to differentiate and associate with ECs, so that blood vessels remain fragile and become dilated $[117,228]$. This process is compatible with the characterization of HHT1 by recurrent epistaxis and internal hemorrhage due to the presence of immature and leaky vessels [229]. These results demonstrate that endoglin is essential for angiogenesis and VSMC recruitment to vessels. Failure of the endothelium to undergo remodeling in Eng $\%$ mice following arrested VSMC development suggests that VSMCs play a key role in regulating endothelial organization and that it is involved in the pathogenesis of HHT1 [28].

Integrins play a key role in angiogenesis and vessel remodeling and maturation [54]. Thus, in growing vessels, the basement membrane undergoes degradation and is replaced by a fibronectin-rich matrix that induces integrin expression in mural cells, specifically fibronectin receptors such as $\alpha_{5} \beta_{1}$ and $\alpha_{v} \beta_{3}$. Both integrins are involved in endothelial and mural cell proliferation and sprouting [230-232].

Integrins also play a major role in monocyte recruitment, a major step in vascular remodeling as previously described. Thus, leukocyte arrest is mediated by the activation of integrins to assume their extended, high-affinity conformation, resulting in the binding of endothelial ligands such as ICAM-1 or VCAM-1 [233]. Human endoglin displays the prototypic RGD motif involved in integrin-based interactions within its ZP juxtamembrane domain [84, 85]. In addition, a physical and functional interplay between endoglin and $\beta_{1}$ integrins has been reported [107, 196, 209, 234]. More recently, endothelial endoglin has been identified as a ligand for leukocyte integrins [27].

In addition to its role in mononuclear cell recruitment, endoglin has also been involved in the regulation of its function. Thus, endoglin is upregulated in activated monocytes from healthy subjects [108], and this activation is impaired in cells from HHT1 patients [235]. In these patients, the type of cells composing the mononuclear cell fraction is modified. Thus, whereas 
in healthy subjects the most predominant cell types are $\mathrm{T}$ lymphocytes, monocytes, and macrophages, with lower proportions of NK cells, dendritic cells and EPCs, the proportion of NK and T lymphocytes in HHT patients was found to be markedly reduced, while the B lymphocyte and monocyte proportions were unaltered and the phagocytic activity of the monocytes was conserved [236]. It has also been reported that HHT1 patients have reduced mononuclear cell recruitment to damaged tissue, which could explain the impaired tissue and vascular repair observed in these patients $[237,238]$. In Eng ${ }^{+/}$mice subjected to an experimental infarct, microvascularity within the infarct zone was strikingly lower than that in wild type mice, which resulted in a greater deterioration in cardiac function [20]. Moreover, after distal middle cerebral artery occlusion, Eng ${ }^{+/-}$mice showed larger infarct/atrophic volumes and fewer infiltrating macrophages than wild type animals, suggesting that endoglin deficiency impairs brain injury recovery by impairing macrophage homing, delaying inflammation resolution, and reducing angiogenesis [239]. Furthermore, in an experimental model of brain arteriovenous malformations in mice induced by local injection of the VEGF gene, it has been reported that, compared with control mice, Eng-deleted mice show fewer macrophages homed to the angiogenic area 2 weeks after angiogenic stimulation [240]. This phenomenon can be explained by the reduced homing of monocytes in the injured tissue in Eng-deficient mice, as previously reported in other models [20, 27, 239]. However, Eng ${ }^{+/-}$ animals showed more tissue macrophages at 8 weeks the stimulus, when arteriovenous malformations were already formed, resulting in persistent inflammation, which can be explained by an impaired clearance of Eng-deficient macrophages in the injured tissue (angiogenic region) $[239,240]$.

Reduced infiltration of leukocytes in HHT1 patients and in Eng ${ }^{+/-}$mice can be explained by their reduced endoglin levels and involvement of the endoglin-integrin interaction in leukocyte recruitment $[27,241]$. However, the previously described effects do not seem to be due only to a decrease in the number of inflammatory cells in the infarct area. A study conducted by van Laake et al [20], showed that mononuclear cell recruitment was similar in wild type and Engt/- mice, but an impaired function of the low-endoglin mononuclear cells produced defects in vessel formation and heart function in Eng ${ }^{+/-}$mice. This phenotype was rescued by the injection of mononuclear cells from healthy human donors but not by mononuclear cells from HHT1 patients. This result is in agreement with the reduction in monocyte function (including oxidative burst and phagocytosis) in HHT patients [242] and in mouse monocytes lacking endoglin [243]. Moreover, a different role for endoglin isoforms in the regulation of monocyte-macrophage functions has been proposed because L- 
endoglin overexpression promotes a pro-inflammatory M1-like macrophage phenotype, whereas S-endoglin favors the expression of anti-inflammatory M2 macrophage markers [96]. Endothelial endoglin may also interact with the integrins present in vascular mural cells. Because endothelial endoglin is a ligand for $\beta_{1}$ integrins and VSMCs express these integrins [56], we can hypothesize that these receptors are involved in the adhesion of mural cells to ECs. A first candidate is $\alpha_{5} \beta_{1}$, a proangiogenic integrin that is required for hypoxia-induced angiogenesis [232] and that is upregulated during angiogenesis and remodeling [225, 226, 230]. Integrin $\alpha_{5} \beta_{1}$ specifically recognizes the RGD motif in extracellular matrix proteins and is expressed by VSMCs, regulating their adhesion and recruitment to blood vessels [56]. Coimmunoprecipitation of endoglin with the $\alpha_{5}$ integrin subunit demonstrated that endoglin could bind to this integrin independently of the RGD motif [209]. These authors reported that endoglin inhibits $\beta_{1}$ integrin subunit lysosomal degradation, thus promoting fibronectin/integrin $\alpha_{5} \beta_{1}$ complex formation, which in turn induces endoglin/ALK1 complex formation and enhances TGF- $\beta 1$ activation of the Smad1/5/8 pathway. Moreover, TGF- $\beta 1$ activates $\alpha_{5} \beta_{1}$ signaling in an endoglin-dependent manner because endoglin interacts with integrin via its extracellular domain to form complexes that are internalized to induce focal adhesion kinase (FAK) activation. A very recent study from our laboratory has demonstrated a critical role for endoglin in integrin-mediated adhesion of mural cells to ECs [28]. We describe an enhanced adhesion between vascular ECs and mural cells by integrin activators, which is inhibited by the suppression of membrane endoglin or $\beta_{1}$-integrin, as well as by the addition of anti-integrin $\alpha_{5} \beta_{1}$ antibody or a peptide containing the RGD motif. Analysis of the binding of adherent mural cells to cells in suspension expressing different endoglin mutants indicates that the endoglin RGD motif plays a major role in the adhesion process. Endoglin haploinsufficiency induces a pericyte-dependent increase in vascular permeability [28], whereas another study reported that retina from $\mathrm{Eng}^{+/-}$mice presents no differences from wild type mice in terms of the abundance of NG2, a protein that is characteristic of pericytes and VSMCs [127]. Further investigations are needed to elucidate the physiological role of endoglin in mural cell recruitment.

ALK5 inhibition, together with VEGF stimuli, induces the expression of $\alpha_{5}$ and $\beta_{3}$ integrins in ECs and promotes angiogenesis in vitro and in vivo [231]. Because both endoglin isoforms differentially regulate the ALK1/ALK5 balance, it is tempting to speculate whether they modulate integrin expression. In this sense, using a human promonocytic cell line, it has been shown that both L-endoglin and S-endoglin inhibit $\alpha_{1}, \beta_{2}, \alpha_{M}$ and $\alpha_{L}$ integrin expression, as 
well as integrin-mediated cellular adhesion and monocytic adhesion to ECs [244]. It remains to be established whether each endoglin isoform drives a cell lineage-dependent regulation of integrin expression.

Endoglin is not only expressed in the endothelium but also in mural cells, although little is known about its role in these cells. It has been reported that secreted protein acidic and rich in cysteine (SPARC) promotes pericyte recruitment in vivo and pericyte migration in vitro by regulating the function of endoglin. SPARC prevents endoglin incorporation into focal complexes, thus promoting pericyte migration. In addition, in the presence of SPARC, endoglin does not bind to latent TGF- $\beta / \alpha_{v}$ integrin complexes, whereas the absence of SPARC allows endoglin to recruit TGF- $\beta$ receptor components to latent TGF- $\beta / \alpha_{v}$ integrin complexes. This process promotes ALK5/Smad2 signaling, which, in turn, blocks pericyte migration and recruitment [110]. Mesoangioblasts (MABs) are vessel-associated stem cells that express pericyte markers and improve skeletal muscle regeneration. Recently, the Smad1/5/8 pathway has been shown to be involved in MAB myogenic differentiation, but there are still no clues for the potential role of endoglin in this process. [245].

\section{CONCLUSIONS AND PERSPECTIVES}

Blood vessel formation and remodeling are essential processes in the maintenance of tissue homeostasis and function, and therefore their alteration causes a variety of pathologic conditions. Endoglin, a TGF- $\beta$ family co-receptor that is expressed mainly in endothelium, plays a key role in angiogenesis and blood vessel homeostasis, becoming a potential therapeutic target for pro- and antiangiogenic approaches for the treatment of diseases such as cancer, diabetes complications or post-ischemic disease. Endoglin expression is increased in the active endothelium, and it has been related to several endothelial processes involved in angiogenesis and vessel remodeling such as EC proliferation and migration, ECM production, leukocyte extravasation or endothelial interactions with mural cells.

TRC105 monoclonal antibody against endoglin acts as an anticancer drug that reduces tumor angiogenesis and is already used for the treatment of many solid tumors with satisfactory results. However, apart from this application, the endoglin facet as a therapeutic target for angiogenesis modulation has not been further exploited, due, at least in part, to the lack of knowledge regarding the precise role of endoglin during angiogenesis.

Unpublished studies from our laboratory reveal that post-ischemic angiogenesis is not 
improved in transgenic mice overexpressing the main isoform of endoglin (Nuñez-Gomez, Pericacho, Ollauri-Ibañez and Lopez-Novoa unpublished observations). It should be noted that, under normal conditions, endoglin expression is increased in response to ischemia, and thus it is likely that the endoglin present in the vessels of ischemic tissues in wild type mice is sufficient for producing the maximal angiogenic response and that endoglin does not improve the process. However, an excess of full-length exogenous endoglin could be useful in situations in which revascularization is reduced, as observed in patients with advanced age, hypercholesterolemia or diabetes [246]. It should be noted that under these conditions, NO production, a critical mediator of angiogenesis and revascularization, is reduced, and lower levels of endoglin are associated with lower NO production [19, 162, 247], thus providing additional support for the hypothesis that endoglin is reduced in these diseases and that the administration of vectors containing endoglin could improve post-ischemic angiogenesis in these situations.

Finally, better knowledge of the mechanisms by which endoglin regulates post-ischemic vascularization could allow the development of effective therapies for diseases in which these phenomena are impaired. 


\section{References}

1. Silvestre JS, Smadja DM, Levy BI (2013) Postischemic revascularization: from cellular and molecular mechanisms to clinical applications. Physiol Rev 93:1743-1802. doi: 10.1152/physrev.00006.2013

2. Schaper W (2009) Collateral circulation: past and present. Basic Res Cardiol 104:5-21. doi: $10.1007 / \mathrm{s} 00395-008-0760-\mathrm{x}$

3. Eilken HM, Adams RH (2010) Dynamics of endothelial cell behavior in sprouting angiogenesis. Curr Opin Cell Biol 22:617-625.

4. Geudens I, Gerhardt H (2011) Coordinating cell behaviour during blood vessel formation. Development 138:4569-4583.

5. Faber JE, Chilian WM, Deindl E, et al (2014) A brief etymology of the collateral circulation. Arterioscler Thromb Vasc Biol 34:1854-9. doi:

10.1161/ATVBAHA.114.303929

6. Resnick N, Yahav H, Shay-Salit A, et al (2003) Fluid shear stress and the vascular endothelium: for better and for worse. Prog Biophys Mol Biol 81:177-199. doi: 10.1016/S0079-6107(02)00052-4

7. Carmeliet P (2000) Mechanisms of angiogenesis and arteriogenesis. Nat Med 6:389395. doi: $10.1038 / 74651$

8. Qiao L, Xie L, Shi K, et al (2012) Notch signaling change in pulmonary vascular remodeling in rats with pulmonary hypertension and its implication for therapeutic intervention. PLoS One 7:e51514.

9. van Varik BJ, Rennenberg RJ, Reutelingsperger CP, et al (2012) Mechanisms of arterial remodeling: lessons from genetic diseases. Front Genet 3:290.

10. Carmeliet P, Jain RK (2011) Molecular mechanisms and clinical applications of angiogenesis. Nature 473:298-307. doi: 10.1038/nature10144

11. Imoukhuede PI, Popel AS (2011) Quantification and cell-to-cell variation of vascular endothelial growth factor receptors. Exp Cell Res 317:955-965. doi: 10.1016/j.yexcr.2010.12.014

12. ten Dijke P, Goumans MJ, Pardali E (2008) Endoglin in angiogenesis and vascular diseases. Angiogenesis 11:79-89. doi: 10.1007/s10456-008-9101-9 
13. Nassiri F, Cusimano MD, Scheithauer BW, et al (2011) Endoglin (CD105): a review of its role in angiogenesis and tumor diagnosis, progression and therapy. Anticancer Res $31: 2283-2290$.

14. Kapur NK, Morine KJ, Letarte M (2013) Endoglin: a critical mediator of cardiovascular health. Vasc Heal Risk Manag 9:195-206. doi: 10.2147/VHRM.S29144

15. Kuiper P, Hawinkels LJ, de Jonge-Muller ES, et al (2011) Angiogenic markers endoglin and vascular endothelial growth factor in gastroenteropancreatic neuroendocrine tumors. World J Gastroenterol 17:219-225. doi: 10.3748/wjg.v17.i2.219

16. Anderberg C, Cunha SI, Zhai Z, et al (2013) Deficiency for endoglin in tumor vasculature weakens the endothelial barrier to metastatic dissemination. J Exp Med 210:563-579. doi: 10.1084/jem.20120662

17. Barnett JM, Suarez S, McCollum GW, Penn JS (2014) Endoglin promotes angiogenesis in cell- and animal-based models of retinal neovascularization. Invest Ophthalmol Vis Sci 55:6490-6498. doi: 10.1167/iovs.14-14945

18. Park S, Dimaio TA, Liu W, et al (2013) Endoglin regulates the activation and quiescence of endothelium by participating in canonical and non-canonical TGF-beta signaling pathways. J Cell Sci 126:1392-1405. doi: 10.1242/jcs.117275

19. Jerkic M, Rodriguez-Barbero A, Prieto M, et al (2006) Reduced angiogenic responses in adult Endoglin heterozygous mice. Cardiovasc Res 69:845-854. doi: 10.1016/j.cardiores.2005.11.020

20. van Laake LW, van den Driesche S, Post S, et al (2006) Endoglin has a crucial role in blood cell-mediated vascular repair. Circulation 114:2288-2297. doi: 10.1161/CIRCULATIONAHA.106.639161

21. Duwel A, Eleno N, Jerkic M, et al (2007) Reduced tumor growth and angiogenesis in endoglin-haploinsufficient mice. Tumour Biol 28:1-8. doi: 10.1159/000097040

22. Seghers L, de Vries MR, Pardali E, et al (2012) Shear induced collateral artery growth modulated by endoglin but not by ALK1. J Cell Mol Med 16:2440-2450. doi: 10.1111/j.1582-4934.2012.01561.x

23. Perez-Gomez E, Del Castillo G, Juan Francisco S, et al (2010) The role of the TGF-beta coreceptor endoglin in cancer. ScientificWorldJournal 10:2367-2384. doi:

10.1100/tsw.2010.230 
24. Lin H, Huang CC, Ou YC, et al (2012) High immunohistochemical expression of TGFbeta1 predicts a poor prognosis in cervical cancer patients who harbor enriched endoglin microvessel density. Int J Gynecol Pathol 31:482-489. doi: 10.1097/PGP.0b013e31824c23a4

25. Fonsatti E, Nicolay HJ, Altomonte M, et al (2010) Targeting cancer vasculature via endoglin/CD105: a novel antibody-based diagnostic and therapeutic strategy in solid tumours. Cardiovasc Res 86:12-19. doi: 10.1093/cvr/cvp332

26. Seon BK, Haba A, Matsuno F, et al (2011) Endoglin-targeted cancer therapy. Curr Drug Deliv 8:135-143.

27. Rossi E, Sanz-Rodriguez F, Eleno N, et al (2013) Endothelial endoglin is involved in inflammation: role in leukocyte adhesion and transmigration. Blood 121:403-415. doi: 10.1182/blood-2012-06-435347

28. Rossi E, Smadja DM, Boscolo E, et al (2016) Endoglin regulates mural cell adhesion in the circulatory system. Cell Mol Life Sci 73:1715-39. doi: 10.1007/s00018-015-2099-4

29. Abramsson A, Berlin O, Papayan H, et al (2002) Analysis of mural cell recruitment to tumor vessels. Circulation 105:112-7.

30. Birbrair A, Zhang T, Wang Z-M, et al (2015) Pericytes at the intersection between tissue regeneration and pathology. Clin Sci (Lond) 128:81-93. doi: 10.1042/CS20140278

31. Lee JW, Bae SH, Jeong JW, et al (2004) Hypoxia-inducible factor (HIF-1)alpha: its protein stability and biological functions. Exp Mol Med 36:1-12. doi: 10.1038/emm.2004.1

32. Levy AP, Levy NS, Wegner S, Goldberg MA (1995) Transcriptional regulation of the rat vascular endothelial growth factor gene by hypoxia. J Biol Chem 270:13333-13340.

33. Liu Y, Cox SR, Morita T, Kourembanas S (1995) Hypoxia regulates vascular endothelial growth factor gene expression in endothelial cells. Identification of a 5' enhancer. Circ Res 77:638-643.

34. Gray MJ, Zhang J, Ellis LM, et al (2005) HIF-1alpha, STAT3, CBP/p300 and Ref-1/APE are components of a transcriptional complex that regulates Src-dependent hypoxiainduced expression of VEGF in pancreatic and prostate carcinomas. Oncogene 24:31103120. doi: 10.1038/sj.onc.1208513

35. Turner N, Grose R (2010) Fibroblast growth factor signalling: from 
development to cancer. Nat Rev Cancer 10:116-129. doi: 10.1038/nrc2780

36. Saylor PJ, Escudier B, Michaelson MD (2012) Importance of fibroblast growth factor receptor in neovascularization and tumor escape from antiangiogenic therapy. Clin Genitourin Cancer 10:77-83. doi: 10.1016/j.clgc.2012.01.010

37. Adams RH, Alitalo K (2007) Molecular regulation of angiogenesis and lymphangiogenesis. Nat Rev Mol Cell Biol 8:464-478.

38. Chappell JC, Wiley DM, Bautch VL (2011) Regulation of blood vessel sprouting. Semin Cell Dev Biol 22:1005-1011. doi: 10.1016/j.semcdb.2011.10.006

39. Blanco R, Gerhardt H (2013) VEGF and Notch in tip and stalk cell selection. Cold Spring Harb Perspect Med 3:a006569. doi: 10.1101/cshperspect.a006569

40. Larrivee B, Prahst C, Gordon E, et al (2012) ALK1 signaling inhibits angiogenesis by cooperating with the Notch pathway. Dev Cell 22:489-500. doi:

10.1016/j.devcel.2012.02.005

41. Asahara T, Masuda H, Takahashi T, et al (1999) Bone marrow origin of endothelial progenitor cells responsible for postnatal vasculogenesis in physiological and pathological neovascularization. Circ Res 85:221-228.

42. Li B, Sharpe EE, Maupin AB, et al (2006) VEGF and PIGF promote adult vasculogenesis by enhancing EPC recruitment and vessel formation at the site of tumor neovascularization. FASEB J 20:1495-1497. doi: 10.1096/fj.05-5137fje

43. Zhang L, Xu Q (2014) Stem/Progenitor cells in vascular regeneration. Arter Thromb Vasc Biol 34:1114-1119. doi: 10.1161/ATVBAHA.114.303809

44. Yamaguchi J, Kusano KF, Masuo 0, et al (2003) Stromal cell-derived factor-1 effects on ex vivo expanded endothelial progenitor cell recruitment for ischemic neovascularization. Circulation 107:1322-1328.

45. Lopez-Holgado N, Alberca M, Sanchez-Guijo FM, et al (2009) Prospective comparative analysis of the angiogenic capacity of monocytes and CD133+ cells in a murine model of hind limb ischemia. Cytotherapy 11:1041-1051. doi: 10.3109/14653240903191719

46. Ma F, Morancho A, Montaner J, Rosell A (2015) Endothelial progenitor cells and revascularization following stroke. Brain Res 1623:150-159. doi:

10.1016/j.brainres.2015.02.010

47. Song JW, Bazou D, Munn LL (2012) Anastomosis of endothelial sprouts forms 
new vessels in a tissue analogue of angiogenesis. Integr Biol (Camb) 4:857-62. doi: $10.1039 / \mathrm{c} 2 \mathrm{ib} 20061 \mathrm{a}$

48. Sacharidou A, Stratman AN, Davis GE (2012) Molecular mechanisms controlling vascular lumen formation in three-dimensional extracellular matrices. Cells Tissues Organs 195:122-143. doi: 10.1159/000331410

49. Stratman AN, Davis GE (2012) Endothelial cell-pericyte interactions stimulate basement membrane matrix assembly: influence on vascular tube remodeling, maturation, and stabilization. Microsc Microanal 18:68-80. doi: $10.1017 /$ S1431927611012402

50. Stratman AN, Malotte KM, Mahan RD, et al (2009) Pericyte recruitment during vasculogenic tube assembly stimulates endothelial basement membrane matrix formation. Blood 114:5091-5101. doi: 10.1182/blood-2009-05-222364

51. Murakami M (2012) Signaling required for blood vessel maintenance: molecular basis and pathological manifestations. Int J Vasc Med 2012:293641. doi: $10.1155 / 2012 / 293641$

52. Wang YH, Yan ZQ, Shen BR, et al (2009) Vascular smooth muscle cells promote endothelial cell adhesion via microtubule dynamics and activation of paxillin and the extracellular signal-regulated kinase (ERK) pathway in a co-culture system. Eur J Cell Biol 88:701-709. doi: 10.1016/j.ejcb.2009.06.001

53. Gaengel K, Genové G, Armulik A, Betsholtz C (2009) Endothelial-mural cell signaling in vascular development and angiogenesis. Arterioscler Thromb Vasc Biol 29:630-638. doi: 10.1161/ATVBAHA.107.161521

54. Silva R, D’Amico G, Hodivala-Dilke KM, Reynolds LE (2008) Integrins: the keys to unlocking angiogenesis. Arter Thromb Vasc Biol 28:1703-1713. doi: 10.1161/ATVBAHA.108.172015

55. Liu J, Zeng L, Kennedy RM, et al (2012) betaPix plays a dual role in cerebral vascular stability and angiogenesis, and interacts with integrin alphavbeta8. Dev Biol 363:95105. doi: 10.1016/j.ydbio.2011.12.022

56. Abraham S, Kogata N, Fassler R, Adams RH (2008) Integrin beta1 subunit controls mural cell adhesion, spreading, and blood vessel wall stability. Circ Res 102:562-570. doi: 10.1161/CIRCRESAHA.107.167908 
57. Hidalgo A, Sanz-Rodriguez F, Rodriguez-Fernandez JL, et al (2001) Chemokine stromal cell-derived factor-1alpha modulates VLA-4 integrin-dependent adhesion to fibronectin and VCAM-1 on bone marrow hematopoietic progenitor cells. Exp Hematol 29:345-355.

58. Zemani F, Silvestre JS, Fauvel-Lafeve F, et al (2008) Ex vivo priming of endothelial progenitor cells with SDF-1 before transplantation could increase their proangiogenic potential. Arter Thromb Vasc Biol 28:644-650. doi: 10.1161/ATVBAHA.107.160044

59. Karin N (2010) The multiple faces of CXCL12 (SDF-1alpha) in the regulation of immunity during health and disease. J Leukoc Biol 88:463-473. doi: 10.1189/jlb.0909602

60. Ceradini DJ, Kulkarni AR, Callaghan MJ, et al (2004) Progenitor cell trafficking is regulated by hypoxic gradients through HIF-1 induction of SDF-1. Nat Med 10:858-864. doi: $10.1038 / \mathrm{nm} 1075$

61. Hamdan R, Zhou Z, Kleinerman ES (2011) SDF-1alpha induces PDGF-B expression and the differentiation of bone marrow cells into pericytes. Mol Cancer Res 9:1462-1470. doi: 10.1158/1541-7786.MCR-11-0190

62. Melchionna R, Di Carlo A, De Mori R, et al (2010) Induction of myogenic differentiation by SDF-1 via CXCR4 and CXCR7 receptors. Muscle Nerve 41:828-835. doi: $10.1002 /$ mus.21611

63. Cheng M, Qin G (2012) Progenitor cell mobilization and recruitment: SDF-1, CXCR4, alpha4-integrin, and c-kit. Prog Mol Biol Transl Sci 111:243-264. doi: 10.1016/B978-012-398459-3.00011-3

64. Alon R, Shulman Z (2011) Chemokine triggered integrin activation and actin remodeling events guiding lymphocyte migration across vascular barriers. Exp Cell Res 317:632-641. doi: 10.1016/j.yexcr.2010.12.007

65. Malinin NL, Pluskota E, Byzova T V (2012) Integrin signaling in vascular function. Curr Opin Hematol 19:206-211. doi: 10.1097/MOH.0b013e3283523df0

66. Wang L, Dong Z, Zhang Y, Miao J (2012) The roles of integrin beta4 in vascular endothelial cells. J Cell Physiol 227:474-478. doi: 10.1002/jcp.22769

67. Faber JE, Zhang H, Lassance-Soares RM, et al (2011) Aging causes collateral rarefaction and increased severity of ischemic injury in multiple tissues. Arterioscler Thromb Vasc Biol 31:1748-56. doi: 10.1161/ATVBAHA.111.227314 
68. Deindl E, Schaper W (2013) Editorial: avenue to arteriogenesis. Curr Vasc Pharmacol $11: 2-4$

69. Grundmann S, Piek JJ, Pasterkamp G, Hoefer IE (2007) Arteriogenesis: basic mechanisms and therapeutic stimulation. Eur J Clin Invest 37:755-66. doi: 10.1111/j.1365-2362.2007.01861.x

70. Hudlicka O, Brown D (1996) Postnatal Growth of the Heart and Its Blood Vessels. J Vasc Res 33:266-287. doi: 10.1159/000159155

71. Tzima E, Irani-Tehrani M, Kiosses WB, et al (2005) A mechanosensory complex that mediates the endothelial cell response to fluid shear stress. Nature 437:426-31. doi: $10.1038 /$ nature 03952

72. Shyy JY, Chien S (2002) Role of integrins in endothelial mechanosensing of shear stress. Circ Res 91:769-775.

73. Yuan S, Kevil CG (2016) Nitric Oxide and Hydrogen Sulfide Regulation of Ischemic Vascular Remodeling. Microcirculation 23:134-45. doi: 10.1111/micc.12248

74. Hoefer IE, van Royen N, Rectenwald JE, et al (2004) Arteriogenesis proceeds via ICAM1/Mac-1- mediated mechanisms. Circ Res 94:1179-85. doi:

10.1161/01.RES.0000126922.18222.F0

75. Troidl K, Tribulova S, Cai W-J, et al (2010) Effects of endogenous nitric oxide and of DETA NONOate in arteriogenesis. J Cardiovasc Pharmacol 55:153-60. doi: 10.1097/FJC.0b013e3181c9556f

76. Baeyens N, Larrivée B, Ola R, et al (2016) Defective fluid shear stress mechanotransduction mediates hereditary hemorrhagic telangiectasia ( HHT ). J Cell Biol. doi: 10.1083/jcb.201603106

77. Demicheva E, Hecker M, Korff T (2008) Stretch-induced activation of the transcription factor activator protein-1 controls monocyte chemoattractant protein-1 expression during arteriogenesis. Circ Res 103:477-84. doi: 10.1161/CIRCRESAHA.108.177782

78. Stabile E, Kinnaird T, la Sala A, et al (2006) CD8+ T lymphocytes regulate the arteriogenic response to ischemia by infiltrating the site of collateral vessel development and recruiting CD4+ mononuclear cells through the expression of interleukin-16. Circulation 113:118-24. doi: 10.1161/CIRCULATIONAHA.105.576702

79. van Weel V, Toes REM, Seghers L, et al (2007) Natural killer cells and CD4+ T- 
cells modulate collateral artery development. Arterioscler Thromb Vasc Biol 27:2310-8. doi: 10.1161/ATVBAHA.107.151407

80. Takahashi T, Kalka C, Masuda H, et al (1999) Ischemia- and cytokine-induced mobilization of bone marrow-derived endothelial progenitor cells for neovascularization. Nat Med 5:434-8. doi: 10.1038/7434

81. Kalka C, Masuda H, Takahashi T, et al (2000) Transplantation of ex vivo expanded endothelial progenitor cells for therapeutic neovascularization. Proc Natl Acad Sci U S A 97:3422-7. doi: 10.1073/pnas.070046397

82. Cheifetz S, Bellon T, Cales C, et al (1992) Endoglin is a component of the transforming growth factor-beta receptor system in human endothelial cells. J Biol Chem 267:1902719030.

83. Lopez-Novoa JM, Bernabeu C (2010) The physiological role of endoglin in the cardiovascular system. Am J Physiol Hear Circ Physiol 299:H959-74. doi:

10.1152/ajpheart.01251.2009

84. Gougos A, Letarte M (1990) Primary structure of endoglin, an RGD-containing glycoprotein of human endothelial cells. J Biol Chem 265:8361-8364.

85. Llorca O, Trujillo A, Blanco FJ, Bernabeu C (2007) Structural model of human endoglin, a transmembrane receptor responsible for hereditary hemorrhagic telangiectasia. J Mol Biol 365:694-705. doi: 10.1016/j.jmb.2006.10.015

86. Castonguay R, Werner ED, Matthews RG, et al (2011) Soluble endoglin specifically binds bone morphogenetic proteins 9 and 10 via its orphan domain, inhibits blood vessel formation, and suppresses tumor growth. J Biol Chem 286:30034-30046. doi: 10.1074/jbc.M111.260133

87. Alt A, Miguel-Romero L, Donderis J, et al (2012) Structural and functional insights into endoglin ligand recognition and binding. PLoS One 7:e29948. doi: 10.1371/journal.pone.0029948

88. Lastres P, Martin-Perez J, Langa C, Bernabeu C (1994) Phosphorylation of the humantransforming-growth-factor-beta-binding protein endoglin. Biochem J 301:765-768.

89. Koleva RI, Conley BA, Romero D, et al (2006) Endoglin structure and function: Determinants of endoglin phosphorylation by transforming growth factor-beta receptors. J Biol Chem 281:25110-25123. doi: 10.1074/jbc.M601288200 
90. Bellon T, Corbi A, Lastres P, et al (1993) Identification and expression of two forms of the human transforming growth factor-beta-binding protein endoglin with distinct cytoplasmic regions. Eur J Immunol 23:2340-2345. doi: 10.1002/eji.1830230943

91. Perez-Gomez E, Eleno N, Lopez-Novoa JM, et al (2005) Characterization of murine Sendoglin isoform and its effects on tumor development. Oncogene 24:4450-4461. doi: 10.1038/sj.onc. 1208644

92. Blanco FJ, Bernabeu C (2011) Alternative splicing factor or splicing factor-2 plays a key role in intron retention of the endoglin gene during endothelial senescence. Aging Cell 10:896-907. doi: 10.1111/j.1474-9726.2011.00727.x

93. Blanco FJ, Bernabeu C (2012) The Splicing Factor SRSF1 as a Marker for Endothelial Senescence. Front Physiol 3:54. doi: 10.3389/fphys.2012.00054

94. Blanco FJ, Bernabeu C (2011) Alternative splicing factor or splicing factor-2 plays a key role in intron retention of the endoglin gene during endothelial senescence. Aging Cell 10:896-907. doi: 10.1111/j.1474-9726.2011.00727.x

95. Blanco FJ, Grande MT, Langa C, et al (2008) S-endoglin expression is induced in senescent endothelial cells and contributes to vascular pathology. Circ Res 103:13831392. doi: 10.1161/CIRCRESAHA.108.176552

96. Aristorena M, Blanco FJ, de Las Casas-Engel M, et al (2014) Expression of endoglin isoforms in the myeloid lineage and their role during aging and macrophage polarization. J Cell Sci 127:2723-2735. doi: 10.1242/jcs.143644

97. Velasco S, Alvarez-Munoz P, Pericacho M, et al (2008) L- and S-endoglin differentially modulate TGFbeta1 signaling mediated by ALK1 and ALK5 in L6E9 myoblasts. J Cell Sci 121:913-919. doi: $10.1242 / j c s .023283$

98. Hawinkels LJ, Kuiper P, Wiercinska E, et al (2010) Matrix metalloproteinase-14 (MT1MMP)-mediated endoglin shedding inhibits tumor angiogenesis. Cancer Res 70:41414150. doi: 10.1158/0008-5472.CAN-09-4466

99. Valbuena-Diez AC, Blanco FJ, Oujo B, et al (2012) Oxysterol-induced soluble endoglin release and its involvement in hypertension. Circulation 126:2612-2624. doi: 10.1161/CIRCULATIONAHA.112.101261

100. Malhotra R, Paskin-Flerlage S, Zamanian RT, et al (2013) Circulating angiogenic modulatory factors predict survival and functional class in pulmonary arterial 
hypertension. Pulm Circ 3:369-380. doi: 10.4103/2045-8932.110445

101. Oujo B, Perez-Barriocanal F, Bernabeu C, Lopez-Novoa JM (2013) Membrane and soluble forms of endoglin in preeclampsia. Curr Mol Med 13:1345-1357.

102. Fonsatti E, Del Vecchio L, Altomonte M, et al (2001) Endoglin: An accessory component of the TGF-beta-binding receptor-complex with diagnostic, prognostic, and bioimmunotherapeutic potential in human malignancies. J Cell Physiol 188:1-7. doi: 10.1002/jcp.1095

103. Wang A, Rana S, Karumanchi SA (2009) Preeclampsia: the role of angiogenic factors in its pathogenesis. Physiology (Bethesda) 24:147-58. doi: 10.1152/physiol.00043.2008

104. Venkatesha S, Toporsian M, Lam C, et al (2006) Soluble endoglin contributes to the pathogenesis of preeclampsia. Nat Med 12:642-649. doi: 10.1038/nm1429

105. Rius C, Smith JD, Almendro N, et al (1998) Cloning of the promoter region of human endoglin, the target gene for hereditary hemorrhagic telangiectasia type 1 . Blood 92:4677-4690.

106. Graulich W, Nettelbeck DM, Fischer D, et al (1999) Cell type specificity of the human endoglin promoter. Gene 227:55-62.

107. Gougos A, St Jacques S, Greaves A, et al (1992) Identification of distinct epitopes of endoglin, an RGD-containing glycoprotein of endothelial cells, leukemic cells, and syncytiotrophoblasts. Int Immunol 4:83-92.

108. Lastres P, Bellon T, Cabanas C, et al (1992) Regulated expression on human macrophages of endoglin, an Arg-Gly-Asp-containing surface antigen. Eur J Immunol 22:393-397. doi: 10.1002/eji.1830220216

109. Conley BA, Smith JD, Guerrero-Esteo M, et al (2000) Endoglin, a TGF-beta receptorassociated protein, is expressed by smooth muscle cells in human atherosclerotic plaques. Atherosclerosis 153:323-335.

110. Rivera LB, Brekken RA (2011) SPARC promotes pericyte recruitment via inhibition of endoglin-dependent TGF-beta1 activity. J Cell Biol 193:1305-1319. doi: $10.1083 /$ jcb.201011143

111. Burrows FJ, Derbyshire EJ, Tazzari PL, et al (1995) Up-regulation of endoglin on vascular endothelial cells in human solid tumors: implications for diagnosis and therapy. Clin Cancer Res 1:1623-1634. 
112. Bodey B, Bodey Jr. B, Siegel SE, Kaiser HE (1998) Upregulation of endoglin (CD105) expression during childhood brain tumor-related angiogenesis. Anti-angiogenic therapy. Anticancer Res 18:1485-1500.

113. Chakhachiro ZI, Zuo Z, Aladily TN, et al (2013) CD105 (endoglin) is highly overexpressed in a subset of cases of acute myeloid leukemias. Am J Clin Pathol 140:370-378. doi: 10.1309/AJCPG8XH7ZONAKXK

114. Miller DW, Graulich W, Karges B, et al (1999) Elevated expression of endoglin, a component of the TGF-beta-receptor complex, correlates with proliferation of tumor endothelial cells. Int J Cancer 81:568-572.

115. Munoz R, Arias Y, Ferreras JM, et al (2012) Transient injury-dependent up-regulation of CD105 and its specific targeting with an anti-vascular anti-mouse endoglin-nigrin b immunotoxin. Med Chem 8:996-1002.

116. Ardelean DS, Yin M, Jerkic M, et al (2014) Anti-VEGF therapy reduces intestinal inflammation in Endoglin heterozygous mice subjected to experimental colitis. Angiogenesis 17:641-659. doi: 10.1007/s10456-014-9421-x

117. Li DY, Sorensen LK, Brooke BS, et al (1999) Defective angiogenesis in mice lacking endoglin. Science 284:1534-1537. doi: 10.1126/science.284.5419.1534

118. Arthur HM, Ure J, Smith AJ, et al (2000) Endoglin, an ancillary TGFbeta receptor, is required for extraembryonic angiogenesis and plays a key role in heart development. Dev Biol 217:42-53. doi: 10.1006/dbio.1999.9534

119. Martin JS, Dickson MC, Cousins FM, et al (1995) Analysis of homozygous TGF beta 1 null mouse embryos demonstrates defects in yolk sac vasculogenesis and hematopoiesis. Ann N Y Acad Sci 752:300-308.

120. Oshima M, Oshima H, Taketo MM (1996) TGF-beta receptor type II deficiency results in defects of yolk sac hematopoiesis and vasculogenesis. Dev Biol 179:297-302. doi: 10.1006/dbio.1996.0259

121. Oh SP, Seki T, Goss KA, et al (2000) Activin receptor-like kinase 1 modulates transforming growth factor-beta 1 signaling in the regulation of angiogenesis. Proc Natl Acad Sci U S A 97:2626-2631.

122. Shovlin CL (2010) Hereditary haemorrhagic telangiectasia: pathophysiology, diagnosis and treatment. Blood Rev 24:203-219. doi: 10.1016/j.blre.2010.07.001 
123. McDonald J, Bayrak-Toydemir P, Pyeritz RE (2011) Hereditary hemorrhagic telangiectasia: an overview of diagnosis, management, and pathogenesis. Genet Med 13:607-616. doi: 10.1097/GIM.0b013e3182136d32

124. Choi EJ, Chen W, Jun K, et al (2014) Novel brain arteriovenous malformation mouse models for type 1 hereditary hemorrhagic telangiectasia. PLoS One 9:e88511. doi: 10.1371/journal.pone.0088511

125. Tual-Chalot S, Oh SP, Arthur HM (2015) Mouse models of hereditary hemorrhagic telangiectasia: recent advances and future challenges. Front Genet 6:25. doi: 10.3389/fgene.2015.00025

126. Bourdeau A, Dumont DJ, Letarte M (1999) A murine model of hereditary hemorrhagic telangiectasia. J Clin Invest 104:1343-1351. doi: 10.1172/JCI8088

127. Lebrin F, Srun S, Raymond K, et al (2010) Thalidomide stimulates vessel maturation and reduces epistaxis in individuals with hereditary hemorrhagic telangiectasia. Nat Med 16:420-428. doi: 10.1038/nm.2131

128. Pece-Barbara N, Vera S, Kathirkamathamby K, et al (2005) Endoglin null endothelial cells proliferate faster and are more responsive to transforming growth factor beta1 with higher affinity receptors and an activated Alk1 pathway. J Biol Chem 280:2780027808. doi: 10.1074/jbc.M503471200

129. Pan CC, Bloodworth JC, Mythreye K, Lee NY (2012) Endoglin inhibits ERK-induced cMyc and cyclin D1 expression to impede endothelial cell proliferation. Biochem Biophys Res Commun 424:620-623. doi: 10.1016/j.bbrc.2012.06.163

130. Pan CC, Kumar S, Shah N, et al (2014) Src-mediated post-translational regulation of endoglin stability and function is critical for angiogenesis. J Biol Chem 289:2548625496. doi: 10.1074/jbc.M114.578609

131. Li C, Hampson IN, Hampson L, et al (2000) CD105 antagonizes the inhibitory signaling of transforming growth factor beta1 on human vascular endothelial cells. FASEB J 14:55-64.

132. Bernabeu C, Lopez-Novoa JM, Quintanilla M (2009) The emerging role of TGF-beta superfamily coreceptors in cancer. Biochim Biophys Acta 1792:954-973. doi: 10.1016/j.bbadis.2009.07.003

133. Lastres $\mathrm{P}$, Letamendia A, Zhang H, et al (1996) Endoglin modulates cellular responses to 
TGF-beta 1. J Cell Biol 133:1109-1121.

134. Gregory AL, Xu G, Sotov V, Letarte M (2014) Review: the enigmatic role of endoglin in the placenta. Placenta 35 Suppl:S93-9. doi: 10.1016/j.placenta.2013.10.020

135. Meurer SK, Alsamman M, Scholten D, Weiskirchen R (2014) Endoglin in liver fibrogenesis: Bridging basic science and clinical practice. World J Biol Chem 5:180-203. doi: 10.4331/wjbc.v5.i2.180

136. Munoz-Felix JM, Oujo B, Lopez-Novoa JM (2014) The role of endoglin in kidney fibrosis. Expert Rev Mol Med 16:e18. doi: 10.1017/erm.2014.20

137. Holderfield MT, Hughes CC (2008) Crosstalk between vascular endothelial growth factor, notch, and transforming growth factor-beta in vascular morphogenesis. Circ Res 102:637-652. doi: 10.1161/CIRCRESAHA.107.167171

138. Pepper MS, Vassalli JD, Orci L, Montesano R (1993) Biphasic effect of transforming growth factor-beta 1 on in vitro angiogenesis. Exp Cell Res 204:356-363. doi:

10.1006/excr.1993.1043

139. Letamendia A, Lastres P, Botella LM, et al (1998) Role of endoglin in cellular responses to transforming growth factor-beta. A comparative study with betaglycan. J Biol Chem 273:33011-33019.

140. Lebrin F, Goumans MJ, Jonker L, et al (2004) Endoglin promotes endothelial cell proliferation and TGF-beta/ALK1 signal transduction. EMBO J 23:4018-4028. doi: 10.1038/sj.emboj.7600386

141. Finkenzeller G, Hager S, Stark GB (2012) Effects of bone morphogenetic protein 2 on human umbilical vein endothelial cells. Microvasc Res 84:81-85. doi: 10.1016/j.mvr.2012.03.010

142. Bai Y, Leng Y, Yin G, et al (2014) Effects of combinations of BMP-2 with FGF-2 and/or VEGF on HUVECs angiogenesis in vitro and CAM angiogenesis in vivo. Cell Tissue Res 356:109-121. doi: 10.1007/s00441-013-1781-9

143. David L, Feige JJ, Bailly S (2009) Emerging role of bone morphogenetic proteins in angiogenesis. Cytokine Growth Factor Rev 20:203-212. doi:

10.1016/j.cytogfr.2009.05.001

144. Cai J, Pardali E, Sanchez-Duffhues G, ten Dijke P (2012) BMP signaling in vascular diseases. FEBS Lett 586:1993-2002. doi: 10.1016/j.febslet.2012.04.030 
145. David L, Mallet C, Mazerbourg S, et al (2007) Identification of BMP9 and BMP10 as functional activators of the orphan activin receptor-like kinase 1 (ALK1) in endothelial cells. Blood 109:1953-1961. doi: 10.1182/blood-2006-07-034124

146. Scharpfenecker M, van Dinther M, Liu Z, et al (2007) BMP-9 signals via ALK1 and inhibits bFGF-induced endothelial cell proliferation and VEGF-stimulated angiogenesis. J Cell Sci 120:964-972. doi: 10.1242/jcs.002949

147. David L, Mallet C, Keramidas M, et al (2008) Bone morphogenetic protein-9 is a circulating vascular quiescence factor. Circ Res 102:914-922. doi: 10.1161/CIRCRESAHA.107.165530

148. Suzuki Y, Ohga N, Morishita Y, et al (2010) BMP-9 induces proliferation of multiple types of endothelial cells in vitro and in vivo. J Cell Sci 123:1684-1692. doi: $10.1242 / j \mathrm{jcs} .061556$

149. van Meeteren LA, Thorikay M, Bergqvist S, et al (2012) Anti-human activin receptorlike kinase 1 (ALK1) antibody attenuates bone morphogenetic protein 9 (BMP9)induced ALK1 signaling and interferes with endothelial cell sprouting. J Biol Chem 287:18551-18561. doi: 10.1074/jbc.M111.338103

150. Barbara NP, Wrana JL, Letarte M (1999) Endoglin is an accessory protein that interacts with the signaling receptor complex of multiple members of the transforming growth factor-beta superfamily. J Biol Chem 274:584-594.

151. Nolan-Stevaux O, Zhong W, Culp S, et al (2012) Endoglin requirement for BMP9 signaling in endothelial cells reveals new mechanism of action for selective antiendoglin antibodies. PLoS One 7:e50920. doi: 10.1371/journal.pone.0050920

152. Jonker L (2014) TGF-beta \& BMP receptors endoglin and ALK1: overview of their functional role and status as antiangiogenic targets. Microcirculation 21:93-103. doi: 10.1111/micc.12099

153. Sanchez-Elsner T, Botella LM, Velasco B, et al (2002) Endoglin expression is regulated by transcriptional cooperation between the hypoxia and transforming growth factorbeta pathways. J Biol Chem 277:43799-43808. doi: 10.1074/jbc.M207160200

154. Botella LM, Sanchez-Elsner T, Rius C, et al (2001) Identification of a critical Sp1 site within the endoglin promoter and its involvement in the transforming growth factorbeta stimulation. J Biol Chem 276:34486-34494. doi: 10.1074/jbc.M011611200 
155. Li C, Issa R, Kumar P, et al (2003) CD105 prevents apoptosis in hypoxic endothelial cells. J Cell Sci 116:2677-2685. doi: 10.1242/jcs.00470

156. Fujita D, Tanabe A, Sekijima T, et al (2010) Role of extracellular signal-regulated kinase and AKT cascades in regulating hypoxia-induced angiogenic factors produced by a trophoblast-derived cell line. J Endocrinol 206:131-140. doi: 10.1677/JOE-10-0027

157. Hung SP, Yang MH, Tseng KF, Lee OK (2013) Hypoxia-Induced Secretion of TGF-beta1 in Mesenchymal Stem Cell Promotes Breast Cancer Cell Progression. Cell Transpl 22:1869-1882. doi: 10.3727/096368912X657954

158. Basu RK, Hubchak S, Hayashida T, et al (2011) Interdependence of HIF-1alpha and TGFbeta/Smad3 signaling in normoxic and hypoxic renal epithelial cell collagen expression. Am J Physiol Ren Physiol 300:F898-905. doi: 10.1152/ajprenal.00335.2010

159. Zhu Y, Sun Y, Xie L, et al (2003) Hypoxic induction of endoglin via mitogen-activated protein kinases in mouse brain microvascular endothelial cells. Stroke 34:2483-2488. doi: 10.1161/01.STR.0000088644.60368.ED

160. Papapetropoulos A, Garcia-Cardena G, Madri JA, Sessa WC (1997) Nitric oxide production contributes to the angiogenic properties of vascular endothelial growth factor in human endothelial cells. J Clin Invest 100:3131-3139. doi: 10.1172/JCI119868

161. Olson N, van der Vliet A (2011) Interactions between nitric oxide and hypoxia-inducible factor signaling pathways in inflammatory disease. Nitric Oxide 25:125-137. doi: 10.1016/j.niox.2010.12.010

162. Jerkic M, Rivas-Elena J V, Prieto M, et al (2004) Endoglin regulates nitric oxidedependent vasodilatation. FASEB J 18:609-611. doi: 10.1096/fj.03-0197fje

163. Santibanez JF, Letamendia A, Perez-Barriocanal F, et al (2007) Endoglin increases eNOS expression by modulating Smad2 protein levels and Smad2-dependent TGF-beta signaling. J Cell Physiol 210:456-468. doi: 10.1002/jcp.20878

164. Zucco L, Zhang Q, Kuliszewski MA, et al (2014) Circulating angiogenic cell dysfunction in patients with hereditary hemorrhagic telangiectasia. PLoS One 9:e89927. doi: 10.1371/journal.pone.0089927

165. Toporsian M, Gros R, Kabir MG, et al (2005) A role for endoglin in coupling eNOS activity and regulating vascular tone revealed in hereditary hemorrhagic telangiectasia. Circ Res 96:684-692. doi: 10.1161/01.RES.0000159936.38601.22 
166. Sadick H, Hage J, Goessler U, et al (2008) Does the genotype of HHT patients with mutations of the ENG and ACVRL1 gene correlate to different expression levels of the angiogenic factor VEGF? Int J Mol Med 22:575-80.

167. Botella LM, Albinana V, Ojeda-Fernandez L, et al (2015) Research on potential biomarkers in hereditary hemorrhagic telangiectasia. Front Genet 6:115. doi: 10.3389/fgene.2015.00115

168. Liu Z, Lebrin F, Maring JA, et al (2014) ENDOGLIN Is Dispensable for Vasculogenesis, but Required for Vascular Endothelial Growth Factor-Induced Angiogenesis. PLoS One 9:e86273. doi: 10.1371/journal.pone.0086273

169. Bockhorn M, Tsuzuki Y, Xu L, et al (2003) Differential vascular and transcriptional responses to anti-vascular endothelial growth factor antibody in orthotopic human pancreatic cancer xenografts. Clin Cancer Res 9:4221-4226.

170. Lyden D, Hattori K, Dias S, et al (2001) Impaired recruitment of bone-marrow-derived endothelial and hematopoietic precursor cells blocks tumor angiogenesis and growth. Nat Med 7:1194-1201. doi: 10.1038/nm1101-1194

171. Yoon CH, Hur J, Park KW, et al (2005) Synergistic neovascularization by mixed transplantation of early endothelial progenitor cells and late outgrowth endothelial cells: the role of angiogenic cytokines and matrix metalloproteinases. Circulation 112:1618-1627. doi: 10.1161/CIRCULATIONAHA.104.503433

172. Fuchs S, Hermanns MI, Kirkpatrick CJ (2006) Retention of a differentiated endothelial phenotype by outgrowth endothelial cells isolated from human peripheral blood and expanded in long-term cultures. Cell Tissue Res 326:79-92. doi: 10.1007/s00441-0060222-4

173. Medina RJ, O’Neill CL, Sweeney M, et al (2010) Molecular analysis of endothelial progenitor cell (EPC) subtypes reveals two distinct cell populations with different identities. BMC Med Genomics 3:18. doi: 10.1186/1755-8794-3-18

174. Martin-Ramirez J, Hofman M, van den Biggelaar M, et al (2012) Establishment of outgrowth endothelial cells from peripheral blood. Nat Protoc 7:1709-1715. doi: $10.1038 /$ nprot.2012.093

175. Zengin E, Chalajour F, Gehling UM, et al (2006) Vascular wall resident progenitor cells: a source for postnatal vasculogenesis. Development 133:1543-1551. doi: 
10.1242/dev.02315

176. Reyes M, Dudek A, Jahagirdar B, et al (2002) Origin of endothelial progenitors in human postnatal bone marrow. J Clin Invest 109:337-346. doi: 10.1172/JCI14327

177. Goon PK, Lip GY, Boos CJ, et al (2006) Circulating endothelial cells, endothelial progenitor cells, and endothelial microparticles in cancer. Neoplasia 8:79-88. doi: $10.1593 /$ neo.05592

178. Gill M, Dias S, Hattori K, et al (2001) Vascular trauma induces rapid but transient mobilization of VEGFR2(+)AC133(+) endothelial precursor cells. Circ Res 88:167-174.

179. Jourde-Chiche N, Dou L, Sabatier F, et al (2009) Levels of circulating endothelial progenitor cells are related to uremic toxins and vascular injury in hemodialysis patients. J Thromb Haemost 7:1576-1584. doi: 10.1111/j.1538-7836.2009.03540.x

180. Foresta C, Schipilliti M, De Toni L, et al (2011) Blood levels, apoptosis, and homing of the endothelial progenitor cells after skin burns and escharectomy. J Trauma 70:459465. doi: 10.1097/TA.0b013e3181fcf83c

181. Paczkowska E, Roginska D, Pius-Sadowska E, et al (2014) Evidence for proangiogenic cellular and humoral systemic response in patients with acute onset of spinal cord injury. J Spinal Cord Med 38:729-44. doi: 10.1179/2045772314Y.0000000227

182. Pelosi E, Castelli G, Martin-Padura I, et al (2012) Human haemato-endothelial precursors: cord blood CD34+ cells produce haemogenic endothelium. PLoS One 7:e51109. doi: 10.1371/journal.pone.0051109

183. Bagley RG, Weber W, Rouleau C, Teicher BA (2005) Pericytes and endothelial precursor cells: cellular interactions and contributions to malignancy. Cancer Res 65:9741-9750. doi: 10.1158/0008-5472.CAN-04-4337

184. Sorensen LK, Brooke BS, Li DY, Urness LD (2003) Loss of distinct arterial and venous boundaries in mice lacking endoglin, a vascular-specific TGFbeta coreceptor. Dev Biol 261:235-250.

185. Fernandez LA, Sanz-Rodriguez F, Zarrabeitia R, et al (2005) Blood outgrowth endothelial cells from Hereditary Haemorrhagic Telangiectasia patients reveal abnormalities compatible with vascular lesions. Cardiovasc Res 68:235-248. doi: 10.1016/j.cardiores.2005.06.009

186. Fernandez LA, Garrido-Martin EM, Sanz-Rodriguez F, et al (2007) Gene 
expression fingerprinting for human hereditary hemorrhagic telangiectasia. Hum Mol Genet 16:1515-1533. doi: 10.1093/hmg/ddm069

187. Weis SM, Cheresh DA (2005) Pathophysiological consequences of VEGF-induced vascular permeability. Nature 437:497-504. doi: 10.1038/nature03987

188. Persson AB, Buschmann IR (2011) Vascular growth in health and disease. Front Mol Neurosci 4:14. doi: 10.3389/fnmol.2011.00014

189. Jerkic M, Peter M, Ardelean D, et al (2010) Dextran sulfate sodium leads to chronic colitis and pathological angiogenesis in Endoglin heterozygous mice. Inflamm Bowel Dis 16:1859-1870. doi: 10.1002/ibd.21288

190. Jerkic M, Letarte M (2015) Increased endothelial cell permeability in endoglin-deficient cells. FASEB J 29:3678-3688. doi: 10.1096/fj.14-269258

191. Lampugnani MG, Orsenigo F, Gagliani MC, et al (2006) Vascular endothelial cadherin controls VEGFR-2 internalization and signaling from intracellular compartments. J Cell Biol 174:593-604. doi: 10.1083/jcb.200602080

192. Gavard J, Gutkind JS (2006) VEGF controls endothelial-cell permeability by promoting the beta-arrestin-dependent endocytosis of VE-cadherin. Nat Cell Biol 8:1223-1234. doi: $10.1038 /$ ncb1486

193. Goumans MJ, Valdimarsdottir G, Itoh S, et al (2002) Balancing the activation state of the endothelium via two distinct TGF-beta type I receptors. EMBO J 21:1743-1753. doi: 10.1093/emboj/21.7.1743

194. Rudini N, Felici A, Giampietro C, et al (2008) VE-cadherin is a critical endothelial regulator of TGF-beta signalling. EMBO J 27:993-1004. doi: 10.1038/emboj.2008.46

195. Liu Y, Jovanovic B, Pins M, et al (2002) Over expression of endoglin in human prostate cancer suppresses cell detachment, migration and invasion. Oncogene 21:8272-8281. doi: 10.1038/sj.onc.1206117

196. Conley BA, Koleva R, Smith JD, et al (2004) Endoglin controls cell migration and composition of focal adhesions: function of the cytosolic domain. J Biol Chem 279:27440-27449. doi: 10.1074/jbc.M312561200

197. Sanz-Rodriguez F, Guerrero-Esteo M, Botella LM, et al (2004) Endoglin regulates cytoskeletal organization through binding to ZRP-1, a member of the Lim family of proteins. J Biol Chem 279:32858-32868. doi: 10.1074/jbc.M400843200 
198. Liu Y, Tian H, Blobe GC, et al (2014) Effects of the combination of TRC105 and bevacizumab on endothelial cell biology. Invest New Drugs 32:851-859. doi: 10.1007/s10637-014-0129-y

199. Ray BN, Lee NY, How T, Blobe GC (2010) ALK5 phosphorylation of the endoglin cytoplasmic domain regulates Smad1/5/8 signaling and endothelial cell migration. Carcinogenesis 31:435-441. doi: 10.1093/carcin/bgp327

200. Lebrin F, Deckers M, Bertolino P, Ten Dijke P (2005) TGF-beta receptor function in the endothelium. Cardiovasc Res 65:599-608. doi: 10.1016/j.cardiores.2004.10.036

201. Oh SP, Seki T, Goss KA, et al (2000) Activin receptor-like kinase 1 modulates transforming growth factor-beta 1 signaling in the regulation of angiogenesis. Proc Natl Acad Sci U S A 97:2626-2631.

202. Goumans MJ, Valdimarsdottir G, Itoh S, et al (2003) Activin receptor-like kinase (ALK)1 is an antagonistic mediator of lateral TGFbeta/ALK5 signaling. Mol Cell 12:817-828.

203. Goumans MJ, Liu Z, ten Dijke P (2009) TGF-beta signaling in vascular biology and dysfunction. Cell Res 19:116-127. doi: 10.1038/cr.2008.326

204. Pardali E, Goumans MJ, ten Dijke P (2010) Signaling by members of the TGF-beta family in vascular morphogenesis and disease. Trends Cell Biol 20:556-567. doi:

10.1016/j.tcb.2010.06.006

205. Mahmoud M, Upton PD, Arthur HM (2011) Angiogenesis regulation by TGFbeta signalling: clues from an inherited vascular disease. Biochem Soc Trans 39:1659-1666. doi: 10.1042/BST20110664

206. Walshe TE, Saint-Geniez M, Maharaj AS, et al (2009) TGF-beta is required for vascular barrier function, endothelial survival and homeostasis of the adult microvasculature. PLoS One 4:e5149. doi: 10.1371/journal.pone.0005149

207. Geng L, Chaudhuri A, Talmon G, et al (2013) TGF-Beta suppresses VEGFA-mediated angiogenesis in colon cancer metastasis. PLoS One 8:e59918. doi: 10.1371/journal.pone.0059918

208. Riedel K, Riedel F, Goessler UR, et al (2007) Tgf-beta antisense therapy increases angiogenic potential in human keratinocytes in vitro. Arch Med Res 38:45-51. doi: 10.1016/j.arcmed.2006.04.010

209. Tian H, Mythreye K, Golzio C, et al (2012) Endoglin mediates 
fibronectin/alpha5beta1 integrin and TGF-beta pathway crosstalk in endothelial cells. EMBO J 31:3885-3900. doi: 10.1038/emboj.2012.246

210. Guerrero-Esteo M, Sanchez-Elsner T, Letamendia A, Bernabeu C (2002) Extracellular and cytoplasmic domains of endoglin interact with the transforming growth factor-beta receptors I and II. J Biol Chem 277:29197-29209. doi: 10.1074/jbc.M111991200

211. Ray BN, Lee NY, How T, Blobe GC (2010) ALK5 phosphorylation of the endoglin cytoplasmic domain regulates Smad1/5/8 signaling and endothelial cell migration. Carcinogenesis 31:435-441. doi: 10.1093/carcin/bgp327

212. Lee NY, Blobe GC (2007) The interaction of endoglin with beta-arrestin2 regulates transforming growth factor-beta-mediated ERK activation and migration in endothelial cells. J Biol Chem 282:21507-21517. doi: 10.1074/jbc.M700176200

213. Lee NY, Golzio C, Gatza CE, et al (2012) Endoglin regulates PI3-kinase/Akt trafficking and signaling to alter endothelial capillary stability during angiogenesis. Mol Biol Cell 23:2412-2423. doi: 10.1091/mbc.E11-12-0993

214. González-Núñez M, Muñoz-Félix JM, López-Novoa JM (2013) The ALK-1/Smad1 pathway in cardiovascular physiopathology. A new target for therapy? Biochim Biophys Acta 1832:1492-1510. doi: 10.1016/j.bbadis.2013.05.016

215. Goumans MJ, Lebrin F, Valdimarsdottir G (2003) Controlling the angiogenic switch: a balance between two distinct TGF-b receptor signaling pathways. Trends Cardiovasc Med 13:301-307.

216. Quintanilla M, Ramirez JR, Perez-Gomez E, et al (2003) Expression of the TGF-beta coreceptor endoglin in epidermal keratinocytes and its dual role in multistage mouse skin carcinogenesis. Oncogene 22:5976-5985. doi: 10.1038/sj.onc.1206841

217. Goldberg PL, MacNaughton DE, Clements RT, et al (2002) p38 MAPK activation by TGFbeta1 increases MLC phosphorylation and endothelial monolayer permeability. Am J Physiol Lung Cell Mol Physiol 282:L146-54.

218. Birukova AA, Birukov KG, Gorshkov B, et al (2005) MAP kinases in lung endothelial permeability induced by microtubule disassembly. Am J Physiol Lung Cell Mol Physiol 289:L75-84. doi: 10.1152/ajplung.00447.2004

219. Santibanez JF, Pérez-Gómez E, Fernandez-L A, et al (2010) The TGF-beta co-receptor endoglin modulates the expression and transforming potential of H-Ras. Carcinogenesis 
31:2145-54. doi: 10.1093/carcin/bgq199

220. Valluru M, Staton CA, Reed MW, Brown NJ (2011) Transforming Growth Factor-beta and Endoglin Signaling Orchestrate Wound Healing. Front Physiol 2:89. doi: 10.3389/fphys.2011.00089

221. Adam PJ, Clesham GJ, Weissberg PL (1998) Expression of Endoglin mRNA and Protein in Human Vascular Smooth Muscle Cells. Biochem Biophys Res Commun 247:33-37. doi: $10.1006 /$ bbrc.1998.8734

222. Matsubara S, Bourdeau A, terBrugge KG, et al (2000) Analysis of endoglin expression in normal brain tissue and in cerebral arteriovenous malformations. Stroke 31:2653-60.

223. Mancini ML, Terzic A, Conley BA, et al (2009) Endoglin plays distinct roles in vascular smooth muscle cell recruitment and regulation of arteriovenous identity during angiogenesis. Dev Dyn 238:2479-2493. doi: 10.1002/dvdy.22066

224. Egorova AD, Khedoe PPSJ, Goumans M-JTH, et al (2011) Lack of primary cilia primes shear-induced endothelial-to-mesenchymal transition. Circ Res 108:1093-101. doi: 10.1161/CIRCRESAHA.110.231860

225. Boroujerdi A, Welser-Alves J V, Tigges U, Milner R (2012) Chronic cerebral hypoxia promotes arteriogenic remodeling events that can be identified by reduced endoglin (CD105) expression and a switch in beta1 integrins. J Cereb Blood Flow Metab 32:1820-1830. doi: 10.1038/jcbfm.2012.94

226. Milner R, Campbell IL (2002) Developmental regulation of beta1 integrins during angiogenesis in the central nervous system. Mol Cell Neurosci 20:616-626.

227. Lopez-Novoa JM, Bernabeu C (2010) The physiological role of endoglin in the cardiovascular system. Am J Physiol Hear Circ Physiol 299:H959-74. doi: 10.1152/ajpheart.01251.2009

228. Carvalho RL, Jonker L, Goumans MJ, et al (2004) Defective paracrine signalling by TGFbeta in yolk sac vasculature of endoglin mutant mice: a paradigm for hereditary haemorrhagic telangiectasia. Development 131:6237-6247. doi: 10.1242/dev.01529

229. Orlova V V, Liu Z, Goumans MJ, ten Dijke P (2011) Controlling angiogenesis by two unique TGF-beta type I receptor signaling pathways. Histol Histopathol 26:1219-1230.

230. Cai WJ, Li MB, Wu X, et al (2009) Activation of the integrins alpha 5beta 1 and alpha v beta 3 and focal adhesion kinase (FAK) during arteriogenesis. Mol Cell Biochem 
322:161-169. doi: 10.1007/s11010-008-9953-8

231. Liu Z, Kobayashi K, van Dinther M, et al (2009) VEGF and inhibitors of TGFbeta type-I receptor kinase synergistically promote blood-vessel formation by inducing alpha5integrin expression. J Cell Sci 122:3294-3302. doi: 10.1242/jcs.048942

232. Li L, Welser-Alves J, van der Flier A, et al (2012) An angiogenic role for the alpha5beta1 integrin in promoting endothelial cell proliferation during cerebral hypoxia. Exp Neurol 237:46-54. doi: 10.1016/j.expneurol.2012.06.005

233. Herter J, Zarbock A (2013) Integrin Regulation during Leukocyte Recruitment. J Immunol 190:4451-7. doi: 10.4049/jimmunol.1203179

234. Muenzner P, Bachmann V, Zimmermann W, et al (2010) Human-restricted bacterial pathogens block shedding of epithelial cells by stimulating integrin activation. Science 329:1197-1201. doi: 10.1126/science.1190892

235. Sanz-Rodriguez F, Fernandez-L A, Zarrabeitia R, et al (2004) Mutation analysis in Spanish patients with hereditary hemorrhagic telangiectasia: deficient endoglin upregulation in activated monocytes. Clin Chem 50:2003-11. doi:

10.1373/clinchem.2004.035287

236. Guilhem A, Malcus C, Clarivet B, et al (2013) Immunological abnormalities associated with hereditary haemorrhagic telangiectasia. J Intern Med 274:351-62. doi:

10.1111/joim.12098

237. Post S, Smits AM, van den Broek AJ, et al (2010) Impaired recruitment of HHT-1 mononuclear cells to the ischaemic heart is due to an altered CXCR4/CD26 balance. Cardiovasc Res 85:494-502. doi: 10.1093/cvr/cvp313

238. Dingenouts CKE, Goumans M-J, Bakker W (2015) Mononuclear cells and vascular repair in HHT. Front Genet 6:114. doi: 10.3389/fgene.2015.00114

239. Shen F, Degos V, Chu P-L, et al (2014) Endoglin deficiency impairs stroke recovery. Stroke 45:2101-6. doi: 10.1161/STROKEAHA.114.005115

240. Zhang R, Han Z, Degos V, et al (2016) Persistent infiltration and pro-inflammatory differentiation of monocytes cause unresolved inflammation in brain arteriovenous malformation. Angiogenesis 19:451-61. doi: 10.1007/s10456-016-9519-4

241. Rossi E, Lopez-Novoa JM, Bernabeu C (2014) Endoglin involvement in integrinmediated cell adhesion as a putative pathogenic mechanism in hereditary 
hemorrhagic telangiectasia type 1 (HHT1). Front Genet 5:457. doi:

10.3389/fgene.2014.00457

242. Cirulli A, Loria MP, Dambra P, et al (2006) Patients with Hereditary Hemorrhagic Telangectasia (HHT) exhibit a deficit of polymorphonuclear cell and monocyte oxidative burst and phagocytosis: a possible correlation with altered adaptive immune responsiveness in HHT. Curr Pharm Des 12:1209-15.

243. Ojeda-Fernández L, Recio-Poveda L, Aristorena M, et al (2016) Mice Lacking Endoglin in Macrophages Show an Impaired Immune Response. PLoS Genet 12:e1005935. doi: 10.1371/journal.pgen.1005935

244. Blanco FJ, Ojeda-Fernandez L, Aristorena M, et al (2015) Genome-wide transcriptional and functional analysis of endoglin isoforms in the human promonocytic cell line U937. J Cell Physiol 230:947-958. doi: 10.1002/jcp.24827

245. Costamagna D, Quattrocelli M, van Tienen F, et al (2015) Smad 1/5/8 are myogenic regulators of murine and human mesoangioblasts. J Mol Cell Biol 8:73-87. doi: 10.1093/jmcb/mjv059

246. Rissanen TT, Vajanto I, Ylä-Herttuala S (2001) Gene therapy for therapeutic angiogenesis in critically ischaemic lower limb - on the way to the clinic. Eur J Clin Invest 31:651-66.

247. Toporsian M, Govindaraju K, Nagi M, et al (2000) Downregulation of endothelial nitric oxide synthase in rat aorta after prolonged hypoxia in vivo. Circ Res 86:671-675. 


\section{FIGURE LEGENDS}

\section{Figure 1.}

Hypoxia is the main angiogenic stimulus. a. High levels of HIF-1 accumulated in hypoxia due to the lack of its degradation stimulate the expression of genes with a hypoxia response element (HRE) in their promoters, such as VEGF, TGF- $\beta$ or endoglin. Adapted from Lee et al, 2004 [31] and Gray et al, 2005 [34]. b. The hypoxic environment stimulates HIF-1 accumulation and the subsequent generation of a VEGF gradient between hypoxic tissue and nearby vessels where VEGF stimulates sprouting and new vessel growth.

\section{Figure 2.}

Overview of the mechanism of angiogenesis and arteriogenesis. a. VEGF signaling through VEGF receptor type 2 (VEGFR-2) induces endothelial cell differentiation into a "tip" phenotype. Tip cells modulate the function of contiguous "stalk" by a mechanism mediated by the Notch-Dll4 and other signaling pathways. In the presence of high levels of membrane endoglin, tip cells degrade the ECM and migrate towards the hypoxic focus guided by the VEGF gradient, whereas stalk cells follow tip cells and proliferate, generating the early new vessel. Adapted from Blanco and Gerhardt, 2013 [39] and Larrivee et al, 2012 [40]). b. Shear stress trigger several endothelial processes during arteriogenesis, including EC release of NO and MCP-1, which mediate vasodilation and recruitment of mononuclear cells, respectively, together with endothelial quiescence and the recruitment of mural cells. Adapted from Carmeliet, 2000 [7], van Varik et al, 2012 [9] and Deindl et al, 2013 [68].

\section{Figure 3.}

Relationship among HIF, endoglin, VEGF and FGF in the endothelium. HIF-1 accumulation during hypoxia induces the expression of endoglin and VEGF genes under HRE control. There is an interrelationship between endoglin, VEGF and FGF because VEGF itself induces endoglin expression, and FGFR2 and FGF induces VEGF expression. The endoglin, VEGF and VEGF/FGF pathways promote endothelial proangiogenic responses. Adapted from Sanchez-Elsner et al, 2002 [153], Li et al, 2003 [155], Gray et al, 2005 [34] and Saylor et al, 2012 [36]. 


\section{Figure 4.}

Structure of the intracellular domain of endoglin membrane isoforms, L-endoglin and S-endoglin. Structure and peptide sequence of the endoglin cytosolic domain. Several Ser and Thr residues within the intracellular domain of endoglin are susceptible to phosphorylation by TßRII, ALK1 and ALK5 receptors and also by other kinases such as Src or PKC. Adapted from Pérez-Gómez et al, 2005 [91], Koleva et al, 2006 [89] and Pan et al, 2014 [130].

\section{Figure 5.}

Role of endoglin in TGF- $\beta$ family signaling in endothelium. Endoglin mediates TGF- $\beta$ and BMP9 signaling though the ALK1 and Smad1/5/8 pathway, leading to an active phenotype of endothelium, with increased proliferation and migration and a role in ECM degradation. This pathway antagonizes the ALK5 and Smad2/3 route involved in endothelial quiescence, ECM deposition mediated by PAI-1 and other cytoquines and mural cell recruitment. Adapted from ten Dijke et al, 2008 [12] and Bernabeu et al, 2009 [132]. 


\section{TABLE 1. Endoglin levels and vascular events}

\section{Effects of reduced levels of endoglin}

Delayed reperfusion and altered vascularization following hindlimb ischemia [19, 22].

Reduced tumor growth rate and tumor capillary density [21].

Impaired revascularization after myocardial infarction [20].

Defects in vessel maturation and mural cell recruitment $[28,117,227,228]$.

Reduced VEGF production by macrovascular ECs [19].

Increased VEGF production by microvascular ECs or angiogenic tissue $[18,188]$.

Reduced EC proliferation and/or migration rates [19, 139, 163, 184, 185].

Increased EC proliferation and/or migration rates [128-130].

Impaired EC sprouting in response to VEGF [167].

Increased endothelial permeability and/or metastasis $[16,18,188,189]$.

Altered EPC differentiation and recruitment [163, 183-185]

$\underline{\text { Circumstances associated to increased endoglin expression }}$

Cardiac and vascular injury [20, 115].

Oxygen-induced angiogenesis in the normal retina $[17,18]$.

Pathological angiogenesis in chronic colitis [116].

Tumor vascularization $[15,16,112,114]$ 
a

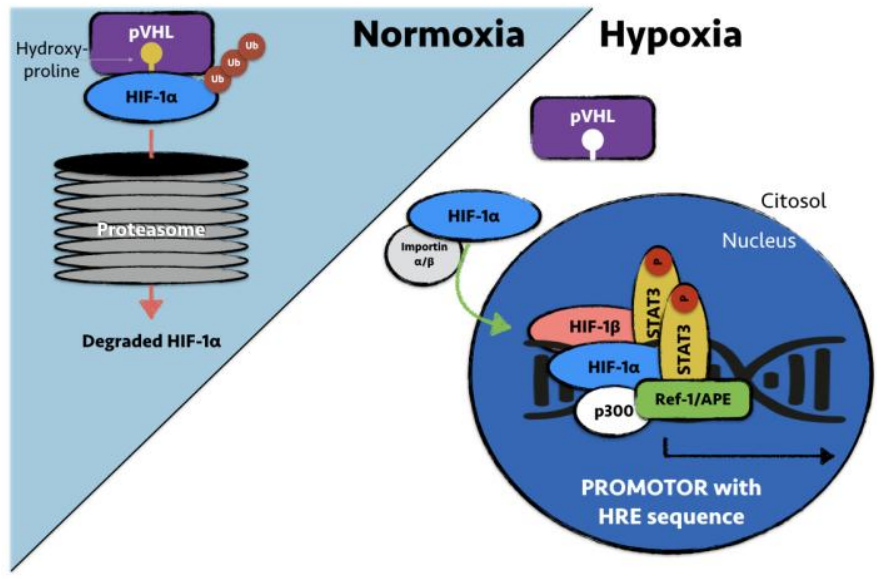

b

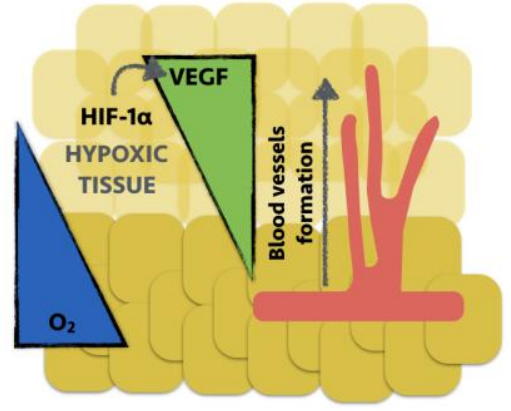

Figure 1 


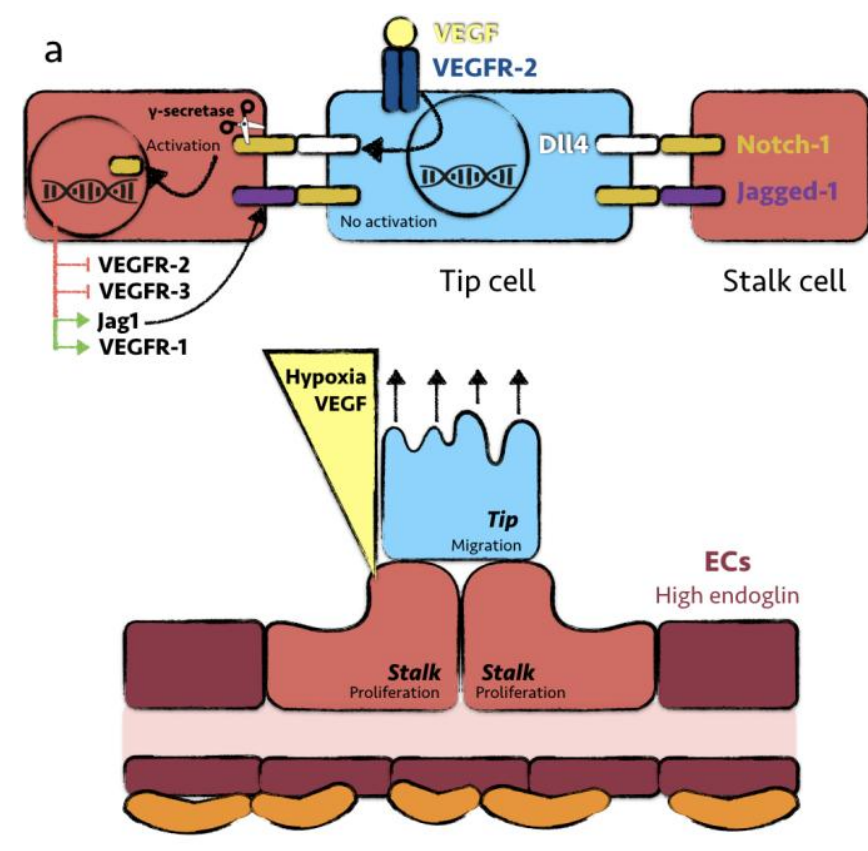

Angiogenesis b

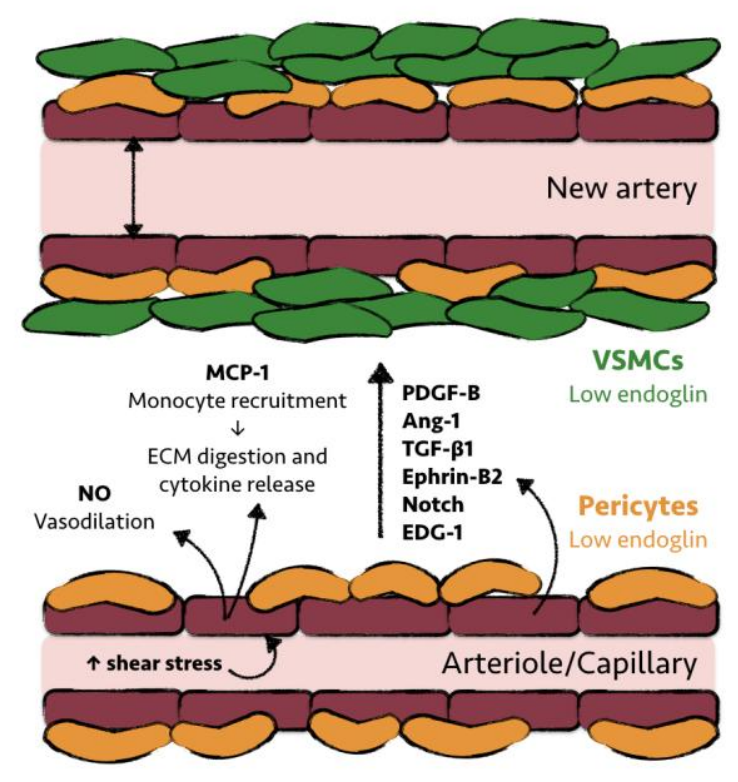

Arteriogenesis

Figure 2 
Hypoxic EC

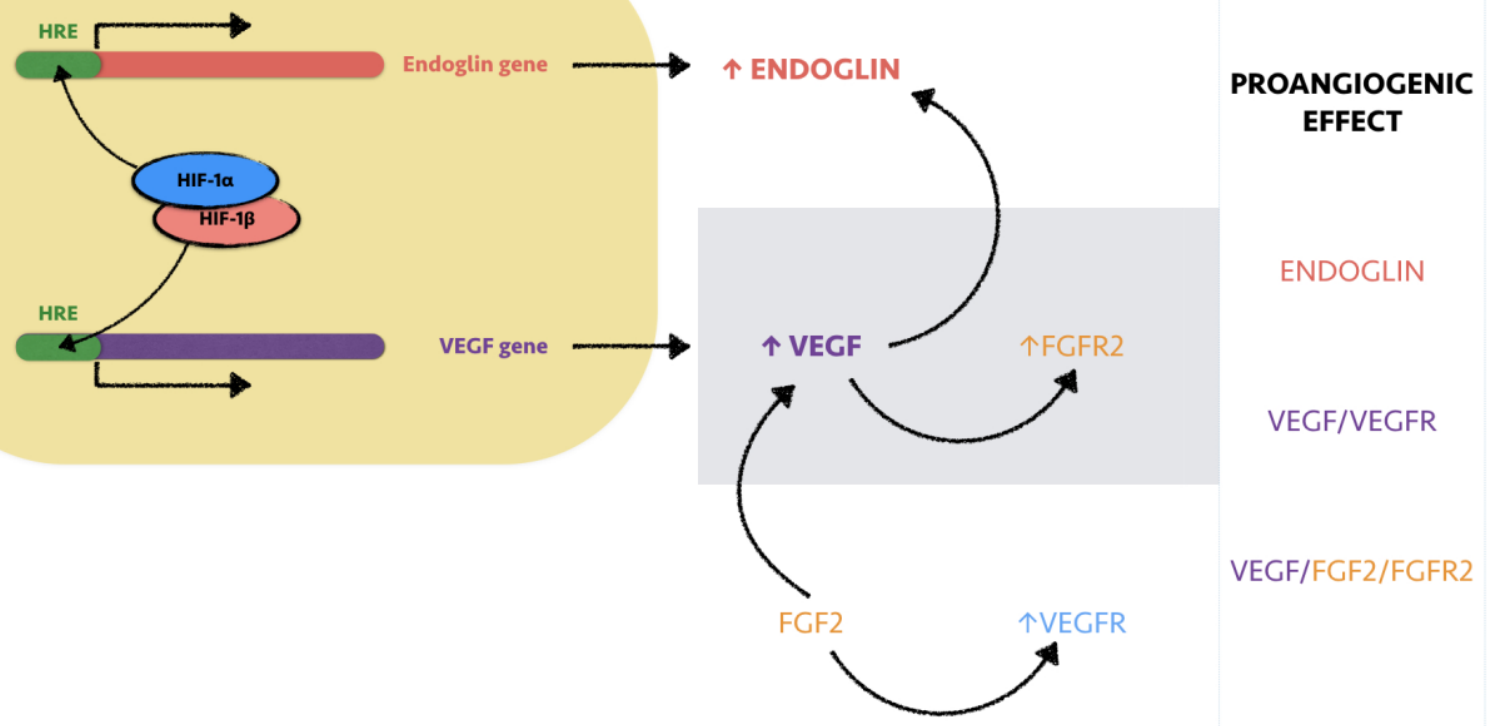

Figure 3 


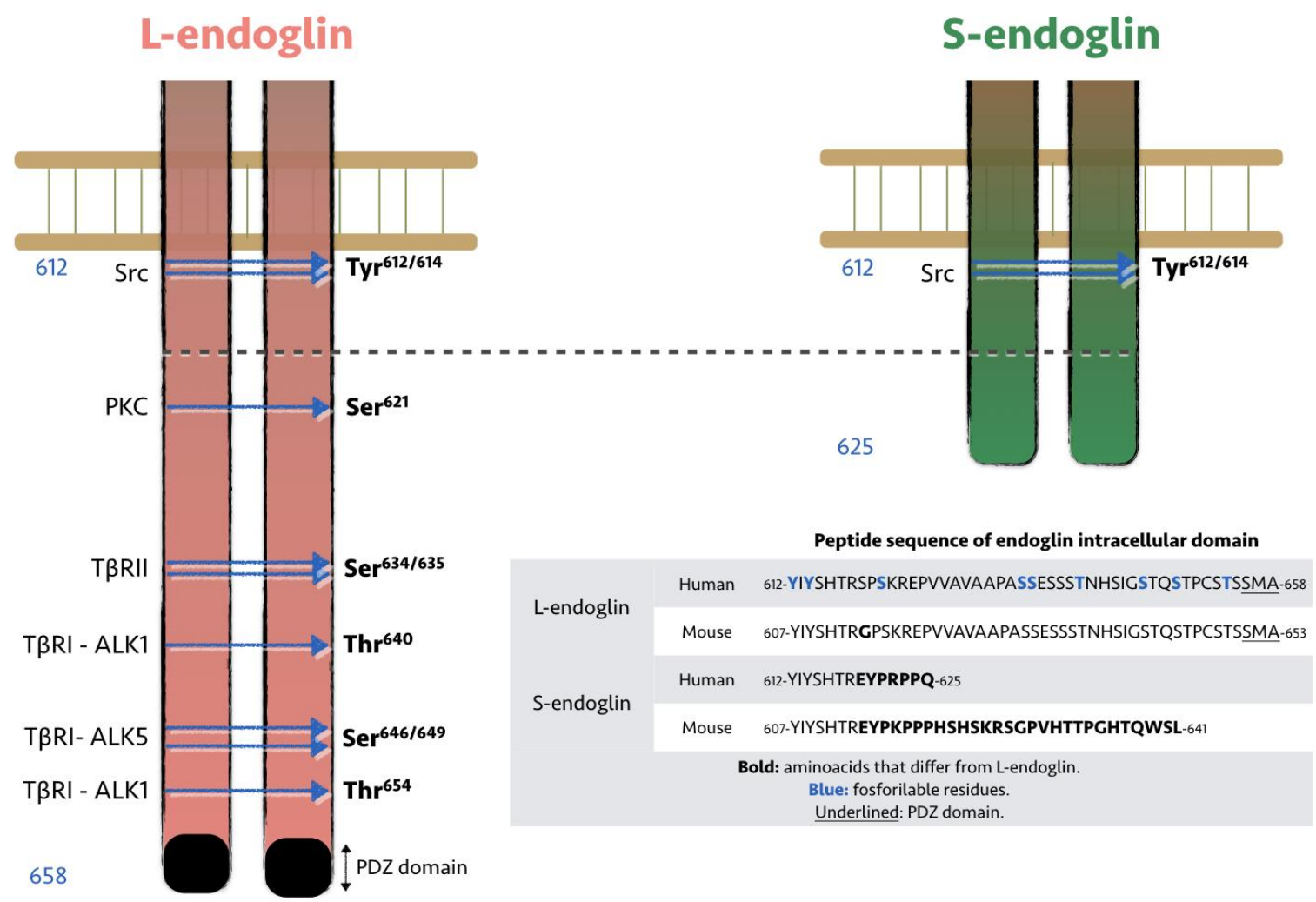

Figure 4 


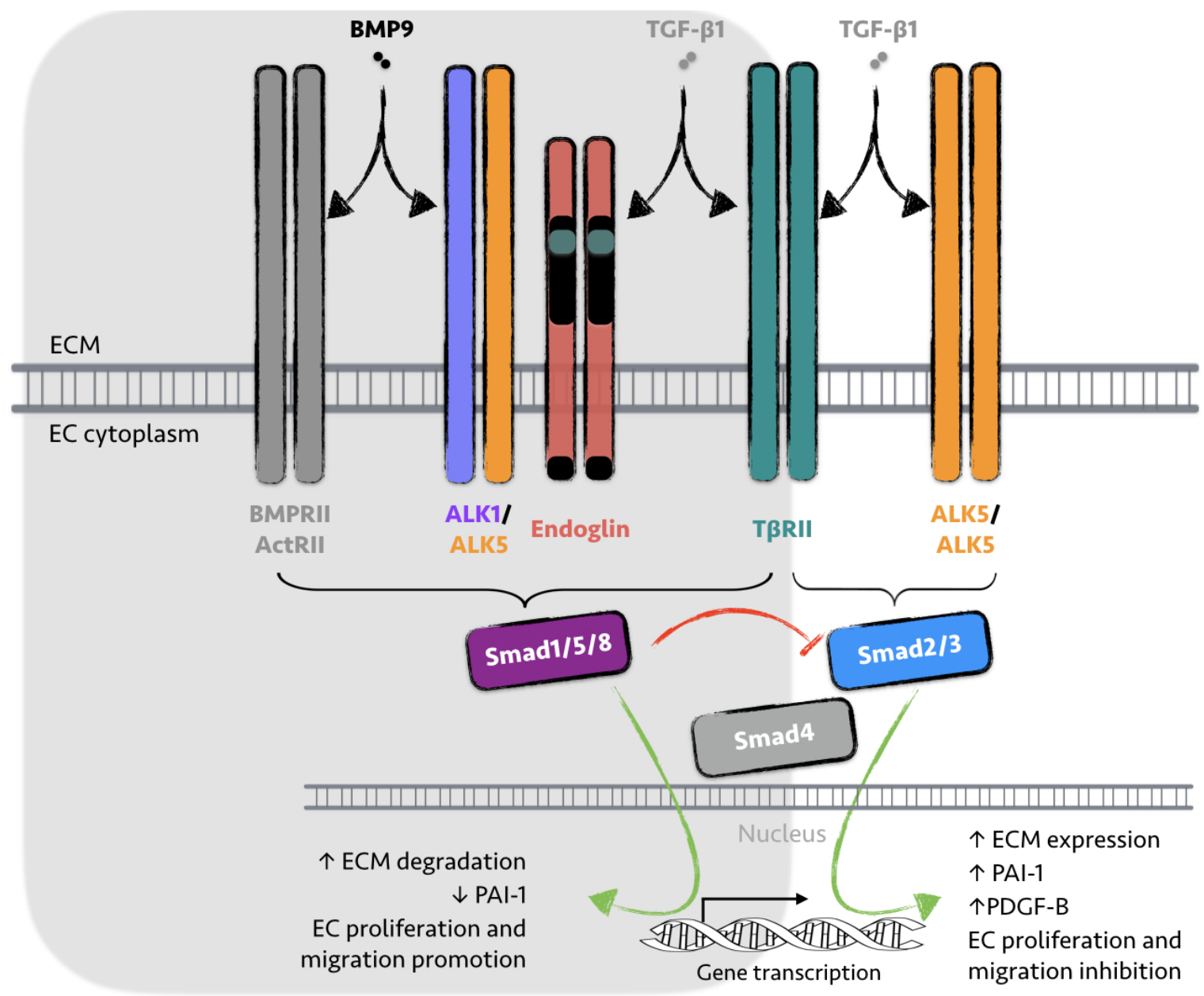

Figure 5 